NBER WORKING PAPER SERIES

THE COMPETITIVE EFFECTS OF TRANSMISSION INFRASTRUCTURE IN THE INDIAN ELECTRICITY MARKET

\author{
Nicholas Ryan \\ Working Paper 23106 \\ http://www.nber.org/papers/w23106 \\ NATIONAL BUREAU OF ECONOMIC RESEARCH \\ 1050 Massachusetts Avenue \\ Cambridge, MA 02138 \\ January 2017
}

I thank Esther Duflo, Michael Greenstone and Rohini Pande for continual support and guidance. I thank Arvind Pande for advice as well as Pramod Deo, S. Jayaraman, V. S. Verma, Rajiv Bansal, Pankaj Batra, Vijay Deshpande and especially Rahul Banerjee of the Central Electricity Regulatory Commission for facilitating this study. Thanks also to Jayant Deo and Akhilesh Awasthy of IEX, Rupa Devi Singh of PXI, S. K. Soonee, S. C. Saxena and S. S. Barpanda of the NLDC and to seminar participants at the CERC, MIT and UCEI. Thanks to Joe Shapiro, Mar Reguant and Steven Puller for detailed comments. The data used in this paper were obtained under a non-disclosure agreement with the Central Electricity Regulatory Commission. The views and analysis herein, including any errors, are mine alone and are not attributable to the parties thanked above in general or to the CERC in particular. The views expressed herein are those of the author and do not necessarily reflect the views of the National Bureau of Economic Research.

NBER working papers are circulated for discussion and comment purposes. They have not been peer-reviewed or been subject to the review by the NBER Board of Directors that accompanies official NBER publications.

(C) 2017 by Nicholas Ryan. All rights reserved. Short sections of text, not to exceed two paragraphs, may be quoted without explicit permission provided that full credit, including () notice, is given to the source. 
The Competitive Effects of Transmission Infrastructure in the Indian Electricity Market Nicholas Ryan

NBER Working Paper No. 23106

January 2017

JEL No. L13,L94,O13

\section{ABSTRACT}

India, seeking to reduce electricity shortages, set up a new power market, in which transmission constraints sharply limit trade between regions. I use confidential bidding data to estimate the costs of power supply and simulate market outcomes with more transmission capacity. I find that the returns to building transmission hinge on market conduct. Under a competitive model of supply, transmission investments roughly breakeven. Under a strategic model, the same transmission expansion increases market surplus by 19 percent, enough to justify the investment, because low-cost sellers increase supply in response to a more integrated grid.

Nicholas Ryan

Department of Economics

Yale University

P. O. Box 208269

New Haven, CT 06520

and NBER

nicholas.ryan@yale.edu 


\title{
The Competitive Effects of Transmission Infrastructure in the Indian Electricity Market*
}

\author{
Nicholas Ryan ${ }^{\dagger}$
}

January 13, 2017

\begin{abstract}
India, seeking to reduce electricity shortages, set up a new power market, in which transmission constraints sharply limit trade between regions. I use confidential bidding data to estimate the costs of power supply and simulate market outcomes with more transmission capacity. I find that the returns to building transmission hinge on market conduct. Under a competitive model of supply, transmission investments roughly breakeven. Under a strategic model, the same transmission expansion increases market surplus by 19 percent, enough to justify the investment, because low-cost sellers increase supply in response to a more integrated grid.
\end{abstract}

JEL Codes: O13, L13, L94

\section{Introduction}

Is power scarce in India? In a narrow sense the answer is clearly yes. At the retail level, roughly 300 million Indian citizens, one-quarter of the population, are not connected to the electric grid, and for those on the grid, the government conservatively estimates supply to be ten percent short of demand (International Energy Agency, 2011; Central Electricity Authority, $2011 b) .{ }^{1}$ Yet this ground-level scarcity is obscured in a broader view of the power sector. In the face of rationing, we might expect plants to be running non-stop, but the utilization of generators is instead low (Malik et al., 2011). Nor has the rapid addition of generating capacity

${ }^{*}$ I thank Esther Duflo, Michael Greenstone and Rohini Pande for continual support and guidance. I thank Arvind Pande for advice as well as Pramod Deo, S. Jayaraman, V. S. Verma, Rajiv Bansal, Pankaj Batra, Vijay Deshpande and especially Rahul Banerjee of the Central Electricity Regulatory Commission for facilitating this study. Thanks also to Jayant Deo and Akhilesh Awasthy of IEX, Rupa Devi Singh of PXI, S. K. Soonee, S. C. Saxena and S. S. Barpanda of the NLDC and to seminar participants at the CERC, MIT and UCEI. Thanks to Joe Shapiro, Mar Reguant and Steven Puller for detailed comments. The data used in this paper were obtained under a non-disclosure agreement with the Central Electricity Regulatory Commission. The views and analysis herein, including any errors, are mine alone and are not attributable to the parties thanked above in general or to the CERC in particular.

${ }^{\dagger}$ Department of Economics, Yale University, Box 208269, New Haven, CT 06520-8269 (e-mail: nicholas.ryan@yale.edu.)

${ }^{1}$ The real costs of this shortage are starting to be documented, for example in terms of foregone manufacturing output (Economist, 2012; Allcott, Collard-Wexler and O'Connell, 2014). Many customers without grid power run their own costly generators instead (Nag, 2010). 
lessened shortages over time (Bhattacharya and Patel, 2008). ${ }^{2}$ Shortages, therefore, are not due to an absolute physical scarcity, but a host of constraints, from distorted retail prices to limits on wholesale trade, that prevent the economic production and allocation of electricity (Wolak, 2008). India recently began to address these constraints by adopting market-oriented reforms in the power sector in order to increase private investment and intra-national trade (Thakur et al., 2005). ${ }^{3}$

Countries around the world have similarly restructured their electricity sectors, from integrated utilities towards open markets, to try to provide better signals for investment and supply (Joskow, 2008). Experience has shown that the efficiency of wholesale electricity markets, and in particular the degree of market power they admit, is very sensitive to market conditions (Borenstein, Bushnell and Wolak, 2002; Puller, 2007) and market design, for example arrangements for bidding or vertical contracting (Reguant, 2014; Bushnell, Mansur and Saravia, 2008) or limits to arbitrage between sequential market segments (Ito and Reguant, 2016). In theory, market power should also depend critically on transmission infrastructure, which determines the extent of competition on the grid (Borenstein, Bushnell and Stoft, 2000; Joskow and Tirole, 2000).

This paper studies the effect of transmission constraints on the competitiveness of a new wholesale power market in India, created by the recent reform. Given the state of the Indian power sector and the proven sensitivity of power markets, an important question is how adverse initial conditions affected the benefits from opening up wholesale trade.

I take the day-ahead market as a window on the effect of transmission constraints on the whole power system. This market is fairly well-integrated with other short-term power trade, but disproportionately affected by transmission constraints, making it the right segment in which to study this problem. Private-sector firms are also overrepresented on the dayahead market. While the market is active and unconcentrated, it does not follow that it is competitive, since 46 percent of the time the grid is congested, meaning more power cannot physically flow between regions. When the grid is congested, suppliers may be able to raise prices in the thinner, regional markets that are broken off by transmission constraints. Indeed,

\footnotetext{
${ }^{2}$ Peak demand exceeded supply by 18 percent in 1996, 13 percent in 2002 and 13 percent in 2011 (Central Electricity Authority, 2011b).

${ }^{3}$ The Electricity Act of 2003 delicensed power generation, allowed open access to the power grid and established power exchanges to encourage trade. An important precursor to this Act was the Electricity Regulatory Commissions Act of 1998, which established state regulators in order to rationalize the process of setting retail tariffs.
} 
I present reduced-form evidence that binding transmission constraints greatly increase market concentration and decrease the magnitude of the elasticity of residual demand faced by sellers in constrained regions, thus raising the incentives of sellers to exercise market power.

The empirical approach of this paper is to build a model of supply bidding in a constrained power grid, to estimate how much market surplus would have changed, if transmission capacity were greater. I use confidential data on hourly bids, offers and transmission constraints in the day-ahead market. I calculate conditions for profit-maximizing supply offers given the competition that strategic sellers face over the grid, and then use these conditions as moments to estimate the marginal costs of electricity supply (Wolak, 2003; Reguant, 2014). Because transmission congestion curtails power flows and thus competition across regions, I innovate by constructing the moment conditions for each seller to reflect the competing offers, and hence the residual demand, they face within their own region of the grid. This local residual demand depends on the distribution of others' bids and the transmission constraints those bids cause to bind, which can have large effects on optimal bidding.

For example, consider a firm in a region that is importing electricity competing with a supplier in another region. Such a firm would typically respond to the competing supplier bidding more aggressively (offering more elastic supply) by bidding more aggressively itself. However, if the competitor increases its offered quantity enough to cause an import constraint to bind, then the firm in the importing region becomes isolated from further competition, and may instead withhold in order to raise prices. This may be important in the Indian market: in the frequently constrained North region, conditional on an import constraint binding, prices are 39 percent higher than in the rest of the grid. It is not clear, from such simple comparisons, to what extent this difference is due to regional differences in cost versus the exercise of market power.

With estimated costs in hand, I simulate counterfactual outcomes to trace out how market surplus would increase if more transmission capacity was built. In these simulations I vary assumptions on market conduct to isolate whether gains in surplus are mainly due to increases in trade across regions with different costs of supply or valuations for electricity, or to the mitigation of market power. Under competitive conduct, sellers are assumed to offer power at cost using the same supply functions in counterfactuals as in the data. Market surplus may increase with more transmission capacity because power can flow from those offering at the 
lowest cost and to those willing to pay the highest price, regardless of where they are located. Under strategic conduct, I restrict strategic sellers to Cournot (quantity) strategies and vary whether these quantities are allowed to respond to the expansion of the grid (endogenous bids) or not (fixed bids). I argue that the Cournot simuluation with endogenous bids is the best representation of counterfactual outcomes in this setting. Market surplus in this scenario may change due to regional differences in cost and demand, as under competition, but may additionally change because sellers, facing greater competition in a more integrated grid, offer more supply. The fixed-quantity bid scenario serves as a benchmark to separate these channels for surplus gains, since it uses the same form of bidding as Cournot but does not allow this strategic response.

The main finding of the paper is that the surplus gains from simulated transmission expansions are much larger under strategic conduct than under competitive conduct. In a strategic model of supply, counterfactual increases in import capacity to the North and South regions large enough to nearly eliminate congestion produce estimated gains of 19 percent of the total baseline market surplus. By comparison with counterfactuals that hold the quantities of strategic sellers fixed, I calculate that 81 percent of this welfare gain is due to transmission expansion decreasing market power. Competitive counterfactuals, wherein supply offers are fixed, but quantity supplied may respond because these offers are price-quantity functions, also show markedly lower gains in surplus than the full strategic counterfactuals. That is to say, the primary cost of transmission constraints is that the best strategy for generators when transmission constraints bind is to withhold power to raise prices against inelastic demand. Consonant with this finding, most of the surplus gains from new transmission accrue in exporting regions, whose sellers are able to supply more and at higher prices when they can reach distant but high-demand customers. Importing regions have modest net gains in surplus because undercutting sellers' market power, and hence surplus, offsets the gains to the buy side of the market from lower prices and greater quantity. (In the import-constrained North region, this effect is large enough that expanding import capacity actually lowers total surplus for the North region overall.)

A second finding is that these potential investments in transmission create net gains in surplus under strategic conduct but are marginal under competitive conduct. I compare the social benefits, or increased surplus, from transmission expansion to the costs of building the 
needed infrastructure. Because transmission investment is subject to cost-plus regulation, good data on the costs of existing transmission system elements is available from regulatory rulings. I apply this cost data to proposed grid expansion plans, in order to estimate the investment needed to relieve congestion at the margin. Under strategic Cournot conduct, expansions of transmission capacity into the North and South regions have estimated benefitcost ratios of 1.65 and 3.24, respectively, indicating that greater transmission capacity between regions would increase social surplus. By contrast, under competitive conduct, the case for additional transmission investment looks marginal, with benefit-cost ratios slightly below one. Thus the gains from infrastructure investment depend on market conduct and, conversely, the success of the market has been limited by transmission infrastructure.

This paper contributes to the literature on the determinants of market power in electricity markets. One line of studies of market power uses observed cost data to simulate market prices and quantities and then compares these simulated market outcomes to observed outcomes. ${ }^{4}$ This paper follows a parallel stream of literature that instead backs out marginal cost from observed bidding behavior and simulates the impact of changes in market structure on market outcomes (Gans and Wolak, 2008; Reguant, 2014). The role of transmission in mitigating market power has been less studied empirically. ${ }^{5}$ Wolak (2012) studies the competitive effects of transmission constraints, in the Alberta market, by predicting in reduced-form the offers strategic suppliers would have made, if lower congestion had raised the elasticity of residual demand they faced. This paper extends the literature by using the structure of the transmission grid in the estimation of costs and emphasizing the role of transmission in determining market power. Knowledge of the grid structure and transmission constraints allow me to estimate costs and structural counterfactual outcomes that account for congestion.

The setting of the study is also novel, in an economically meaningful way, because the

\footnotetext{
${ }^{4}$ Wolfram (1999) finds prices in the UK market above cost but below the predictions of most oligopoly models. Borenstein, Bushnell and Wolak (2002) find that market power in California's restructured wholesale electricity market resulted for 59 percent of the nearly $\$ 7$ billion rise in expenditures between 1999 and 2000 . Bushnell, Mansur and Saravia (2008) show that vertical arrangements are an important reason why these high prices do not generally obtain in U.S. markets.

${ }^{5}$ Davis and Hausman (2014) study the costs of a nuclear plant closure in California that induced transmission constraints to bind. Mansur and White (2012) show how centralized as opposed to bilateral market-clearing improves market efficiency, an effect mainly due to better aggregation of information about transmission constraints. A related literature on congestion in operations research has focused on solution concepts for complex transmission networks (Neuhoff et al., 2005; Benjaming F. Hobbs and Pang, 2000; Xu and Baldick, 2007). A range of other empirical papers on electricity markets have noted the importance of congestion in the markets under study without analyzing it explicitly (Hortaçsu and Puller, 2008; Bushnell, Mansur and Saravia, 2008; Allcott, 2012; Reguant, 2014).
} 
Indian power market has some features that differ sharply from the norm in markets in developed countries, such as a lack of financial contracting and elastic demand from electricity distribution companies (i.e., distribution companies that allow blackouts rather than pay a high price for power). I believe this paper is the first micro-econometric study of a wholesale power market in a developing country. ${ }^{6}$ Empirical evidence on market power in this setting is therefore important, because it is not clear a priori whether, for example, more elastic wholesale demand due to the use of retail-level rationing might reduce the ability of wholesale suppliers to raise prices.

There is a growing literature in development economics on the effects of market integration due to many types of public infrastructure projects, of which transmission can be taken as an example. ${ }^{7}$ Most of this literature considers competitive markets like agriculture, whereas I focus empirically on the effects of infrastructure specific to imperfectly competitive markets like electricity generation. In such markets, the gains from economic integration may come as much through reductions in market power as through changes in production cost.

The rest of the paper runs as follows. Section 2 describes the Indian power sector and the nature of transmission congestion. Section 3 introduces the data. Section 4 introduces a model of supplier bidding and a related counterfactual model of supply and Section 5 describes the estimation strategy. Section 6 presents estimated firm costs. Section 7 presents the estimated benefits and costs of counterfactual transmission expansions and Section 8 concludes.

\section{The Indian electricity sector}

The Indian electricity sector is characterized by persistent imbalances. Artificially low agricultural and domestic tariffs and large distribution losses have perpetuated retail shortages and huge financial losses in electricity distribution (Wolak, 2008). Generation, traditionally the province of the state and central governments, was opened to private investment, but such

\footnotetext{
${ }^{6}$ Several papers survey the experience of developing and transition countries with different stages of electricity liberalization (Bacon and Besant-Jones, 2001; Jamasb, 2005; Williams and Ghanadan, 2006). Other studies, such as Zhang, Parker and Kirkpatrick (2008), estimate cross-country regressions to evaluate electricity reform in a structure-conduct-performance paradigm.

${ }^{7}$ Mobile phone infrastructure increases the efficiency of market allocation under perfect competition (Jensen, 2007). Transport infrastructure that lowers the cost of trade raises incomes, but with complex effects on the pattern of factor allocation and production across space (Jensen, 2007; Donaldson, 2012; Faber, 2014; Banerjee, Duflo and Qian, 2012; Donaldson and Hornbeck, 2013). Electricity distribution networks have been found to increase labor supply, labor productivity and housing values (Lipscomb, Mobarak and Barham, 2013; Dinkleman, 2011). McRae (2014) studies the adverse incentive effects of subsidies for electricity consumption on distribution investment and service quality in Colombia.
} 
investment remained low given that the most prominent buyers, distribution companies, were bankrupt monopsonists in their respective states (Bhattacharya and Patel, 2008).

The Electricity Act of 2003 was a major reform intended to correct some of the structural problems with the electricity sector in India and to create a larger role for market forces. This reform touched on nearly every aspect of electricity generation, transmission and distribution but was particularly meant to foster competition and private supply by opening access to the power grid across the country (Thakur et al., 2005). The Act sanctioned wholesale markets for electricity and in 2008 a day-ahead market, which gets its name for hosting trade one day ahead of when the power is to be delivered, opened. The following subsections place the day-ahead market, the focus of this paper, in the context of the Indian electricity sector.

\section{(a) Generation and Ownership}

India's power sector is small for a country of its size. The peak generation in India of 110 GW on capacity of 187 GW in 2010, serving about 900 million grid-connected customers of a population of 1.2 billion, is comparable to the $127 \mathrm{GW}$ peak on $167 \mathrm{GW}$ of capacity in the Pennsylvania-New Jersey-Maryland (PJM) market, which serves 51 million people (Central Electricity Authority, 2011b, 2012b; International Energy Agency, 2011). Thermal plants generate the bulk of electricity: in 2010-11, coal plants generated 69 percent of the country's electricity, gas 12 percent, and hydroelectric 14 percent, with the balance from nuclear and imports (Central Electricity Authority, 2011c). Outside the formal power sector, India also has a large number of captive generating units. ${ }^{8}$

Electricity generation remains dominated by state actors but the role of the private sector has grown rapidly in the last decade. In 2003, the year the Electricity Act was passed, the private sector held 10 percent of total generation capacity, but that increased to 18 percent in 2010 and leapt up to 31 percent by 2013 (Central Electricity Authority, 2011a). (This tripling of capacity share represents a six-fold increase in private-sector megawatts against a backdrop of overall capacity roughly doubling.) The short-term electricity markets, described in detail below, have private sector participation above the private share in capacity overall. Large state producers sell most of their capacity through long-term physical contracts well

\footnotetext{
${ }^{8}$ Captive units are owned by particular industrial, commercial or residential facilities for their own use. Total captive generation capacity was estimated at 25 GW in 2010 (13 percent of grid generation capacity) (Nag, 2010).
} 
in advance of delivery, whereas private plants wait to sell until closer to delivery. Thus in the day-ahead market state utilities provided 20 percent of cleared sell volumes in 2009 and a mere 7 percent in 2010 (author's calculation). Aside from private firms devoted to selling power, industrial plants in other businesses commonly buy and sell power in the wholesale market from their captive capacity.

\section{(b) Segments of the Wholesale Electricity Market}

There are three ways to trade wholesale electricity in India: bilateral contracts between buyers and sellers, the day-ahead market and a real-time balancing mechanism called unscheduled interchange. These segments differ in when electricity is traded relative to the date of delivery, how prices are set and regulatory limits on trade. While the empirical analysis will treat the day-ahead market in isolation, it is helpful to understand where this market fits in the context of other market segments.

Consider the market segments moving forward in time towards the date when electricity is physically delivered. Most trade happens through bilateral contracts set more than one year in advance of delivery, which are called long-term. In fiscal 2010, 90 percent of total electricity generation (809.45 terawatt-hours) was traded on long-term contracts, typically between state-owned generators and distribution companies for a large share of a generator's output (Central Electricity Regulatory Commission, 2011). The remaining trade, less than one year in advance of delivery, is called short-term. Bilateral contracts set less than one year in advance of delivery, called short-term contracts, comprise a further 5 percent of generation. These contracts are mediated by power traders and most often apply to daily or monthly blocks covering all hours in a day. The last opportunity for scheduled power trade is the day-ahead market, which handles 2 percent of generation. Scheduled power is reported to the system operator before delivery. The balance of about 3 percent of generation is not scheduled, but demanded and supplied in real time in regulated quantities and at administered prices through a mechanism called unscheduled interchange (UI) (Described in Appendix A).

Despite very different market rules across segments, the short-term market, consisting of short-term contracts, the day-ahead market and balancing, is fairly well integrated. Contract price levels have been near or above day-ahead prices. ${ }^{9}$ These prices move closely together.

\footnotetext{
${ }^{9}$ For example, the prices of electricity transacted on the power exchanges in fiscal 2010 averaged USD 69.40 per megawatt-hour (MWh), lower than the prices through contracts (USD 95.8/MWh).
} 
Appendix Table A1 shows the correlations between prices across the different short-term market segments. The correlation between day-ahead prices on the Indian Energy Exchange, from which this paper uses data, and the Power Exchange India, the other day-ahead exchange, is 0.92 at hourly frequency and 0.98 at weekly frequency. This high correlation, which is natural given that bidders can move freely between the exchanges, implies that the use of only IEX data in this paper represents conduct on both day-ahead market exchanges accurately. The power exchange prices are also fairly highly correlated with prices on other market segments. The correlation between the IEX price and balancing prices is 0.60 at hourly frequency and 0.81 at weekly frequency, and with short-term market prices is 0.71 at weekly frequency.

If sequential markets were perfectly integrated, and neglecting uncertainty, we may expect prices to move exactly together. However, in practice there are limits to arbitrage across segments in electricity markets (Ito and Reguant, 2016). In the Indian market, these limits include rules limiting how much market participants can adjust their advance schedules in real time and differing treatment of transmission congestion across segments. The Appendix describes regulatory limits to arbitrage between the scheduled day-ahead market and unscheduled interchange, including penalties designed to prevent sellers from withholding power from the schedule and supplying it through UI instead. Neglecting these differences, it is clear that the short-term market segments move closely together. Moreover, when there is no transmission corridor available on the day-ahead market, there is no corridor left for other markets either. Therefore, analysis on how transmission congestion affects conduct in the day-ahead market segment will apply in part to other market segments, for which micro-data is not available. I interpret the implications of the empirical results for other market segments in Section 7 (c).

It may be hard to imagine how the electricity market clears with such a small share of trade in the day-ahead market (two percent) and indeed in all short-term segments together (ten percent less than one year, five percent less than one day). The simplest explanation is that the market does not clear, since the sector has an extra degree of freedom in shedding up to 13 percent of load in peak hours (Central Electricity Authority, 2011b). Market institutions also tend to discourage short-term trade. For example, due to restrictive financial regulation, India has no forward financial contracting tied to electricity spot prices (Sharma and Vashishtha, 2007). Thus suppliers in the Indian market day-ahead market earn the day-ahead price on 
their entire cleared quantity, which makes waiting to buy or sell power risky. ${ }^{10}$

The overall picture of short-term power trade is then of linked but still imperfectly integrated markets. Buyers and sellers arbitrage to some extent between the short-term contract, day-ahead and UI segments, but these markets do not offer perfect substitutes.

\section{(c) Transmission Capacity and Charges}

Power that is traded on any platform must flow through the electricity grid. The high-voltage, long-distance transmission lines that carry power between regions have physical limits on how much power they can carry, determined by engineering standards. These physical limits are not the last word on the declared capacity of a line: the system operator, here the National Load Dispatch Centre (NLDC), accounts for externalities in the power grid and a reliability margin in determining how much power can flow on various paths. The transmission capacity set between regions is then allocated in an administrative manner prioritizing first longterm trade, then short-term contracts and lastly the day-ahead market (Central Electricity Regulatory Commission, 2008a, see Appendix A for details). The net effect of the allocation process is that the day-ahead market becomes the residual claimant on transmission capacity across the system and is greatly exposed to transmission congestion.

The pricing of transmission does not reflect its scarcity. In the Indian market, transmission charges are flat per MWh "postage stamp" charges that apply to use of the grid and transmission across regions, regardless of the available capacity at the time of use. ${ }^{11}$ I neglect these transmission charges in the analysis below as they are small, about four percent of the mean energy price, and would not change in any counterfactual scenario.

\section{(d) The Day-Ahead Electricity Market}

The day-ahead market is the best channel through which to study the role of congestion in the Indian market as all bids are associated with a region of the grid and it is the only

\footnotetext{
${ }^{10}$ By contrast, in the PJM (United States), NEM1 (Australia) and Spanish markets, 90 percent, 88 percent and 91 percent of physical output has been covered by financial contracts by the time power is traded in the spot market, meaning that the supplier offering power is not exposed to the spot market price (Allcott, 2012; Wolak, 2007; Reguant, 2014).

${ }^{11}$ During the period of study, for bilateral contracts, the selling party was responsible for a charge of USD 1.6/MWh for connecting to the national grid and an additional USD 1.6/MWh for each region through which the power traded is to flow, up to USD 4.8/MWh (Central Electricity Regulatory Commission, 2008a). On the power exchange, transactions are subject to comparable transmission charges of USD 2/MWh separately for the buyer and seller.
} 
segment where market clearance directly prices the scarcity due to congestion. The market is a double-sided auction conducted every day for each of 24 hourly blocks the following day. ${ }^{12}$ Bidders can submit both single bids, which are functions from price to quantity for a single hour, and block bids, which specify the maximum willingness-to-pay of a buyer or minimum willingness-to-accept of a seller on average over a continuous block of hours.

As shown in Figure 1, Panel A, the power exchange designates bids as coming from one of ten subregions. I group these ten subregions into the six regions for which transmission constraints ever bind - North, East, Northeast, West, South 1 and South 2 - shown in Figure 1, Panel B. ${ }^{13}$ The physical grid is more complex than shown in Figure 1, Panel B, but this structure represents the binding links in the system very well and is therefore used by the system operator to designate available transmission capacity, check for binding transmission constraints and report these constraints to the exchange. The West and East regions form a central core. Exports from this core to the demand centers of the North and South 1 regions are often constrained by transmission capacity. The South 2 region is further removed from the core and only accessible via wheeling (i.e., transshipment) of power through South 1 . The Northeast region, a source of cheap hydropower, is linked to the core through the East.

Institutional evidence suggests that market participants in the day-ahead market should be treated as strategic profit-maximizers and not competitive price-takers. As described above, many of the bidders are private, independent power producers. The Central Electricity Regulatory Commission serves as a market monitor and is concerned about the exercise of market power, to the degree that it imposed a binding price cap (of USD 160/MWh) in parts of September and early October, 2009. I will also treat public-sector firms as profitmaximizing. State firms may have other social objectives in selling power, such as keeping the power within their state, or reaching low-income consumers. However, these objectives are served by the supply of power on long-term contracts between state buyers and sellers. State actors in the short-term markets tend to be utilities from power-surplus states that are trying to profitably utilize excess capacity (Indian Energy Exchange, 2014).

\footnotetext{
${ }^{12}$ The market is actually run on two separate power exchanges, the Indian Energy Exchange (IEX) and Power Exchange India Limited (PXI). As IEX has over 90 percent market share, among the two exchanges, I study bidding on this exchange alone throughout the paper. This focus will somewhat understate the costs of congestion.

${ }^{13}$ Two of these, South 1 and South 2, are technically subregions of the South but I will call them regions.
} 


\section{(e) Market Clearance}

Market clearance accounts for transmission congestion by splitting off areas that are constrained and clearing them separately.

The first step is unconstrained clearance, assuming that transmission constraints do not bind. This clearance is typical of a double-sided auction and is shown in Figure 2, Panel A for an example hour (January 26th, 2010, 16:00-17:00). The clearing price is the least price at which supply and demand intersect. The clearing volume is the lesser of the supply and demand volume at the clearing price. In this hour and many others, demand is strikingly elastic in the area around USD 80/MWh (INR 4000/MWh). ${ }^{14}$ The large, flat steps in the demand curve are bids of electricity distribution companies, which, though not willing to procure power above this price, may simultaneously be shedding load. The supply and demand curves have been shifted out by the volume of cleared block bids. ${ }^{15}$

If transmission constraints in fact bind, at the market-clearing solution that was assumed to be unconstrained, the power exchanges proceed to "market-splitting," an iterative algorithm to separate areas with binding constraints and clear them separately at region-specific prices. ${ }^{16}$ The idea is that prices in regions importing (exporting) at the unconstrained solution are raised (lowered) until the equilibrium imports (exports) are no more than the available transmission capacity. Appendix B describes the algorithm for iterating over constraints and gives an example of how market-splitting works, for the hour for which Figure 2 illustrated the unconstrained market clearance.

\section{Data and Study Sample}

The analysis uses confidential data on bids and transmission constraints from the Indian Energy Exchange (IEX) and the system operator (NLDC), respectively.

From the exchange, I use the bids and offers from participants in the day-ahead market. Bids are step functions from price to quantity with up to 32 allowed steps from the price

\footnotetext{
${ }^{14}$ All bids in the market are originally in Indian rupees (INR). The paper uses a round exchange rate of USD 1 per INR 50, which is slightly stronger than that which prevailed on average in the study period (USD 1 per INR 46).

${ }^{15}$ Block bids are cleared by an iterative algorithm described in the Appendix. Blocks are a relatively small part of the Indian market and, while I incorporate blocks in the market clearance throughout, I will take them as exogenous in the counterfactual simulations.

${ }^{16}$ Market-splitting is a zonal pricing method similar to that used in ERCOT (Texas) until 2010 and still used in the Nordpool market in Europe.
} 
floor of USD $0 / \mathrm{MWh}$ to the ceiling of USD 400/MWh. ${ }^{17}$ From the system operator, I use transmission constraints as supplied to the exchange on the afternoon of the day of bidding. These constraints include, for every hourly block, both margin constraints on the maximum exports and imports permissible for each regional node and path constraints on the maximum flows over each inter-regional path in each direction. ${ }^{18} \mathrm{I}$ limit the sample of hourly auctions to the inclusive six-month period from November, 2009 through April, 2010 to study the bidding response to congestion within a constant regulatory framework. ${ }^{19}$

Table 1 presents summary statistics on bidding over the sample period that describe an active and unconcentrated market. The average unconstrained clearing price across auctions (Panel A) is USD 87.06/MWh, with a standard deviation of USD 48.52/MWh (Cf. the average price in the PJM market of USD 66.72/MWh for 2010 (Monitoring Analytics, 2011)). Auctions have wide participation, with an average of 19 buy bids and 25 sell bids in each auction (column 1), and as many as 48 and 54 bids in some auctions (column 5). Most bidders use few steps (Panel B), with sellers offering a bid on average with only 1.84 steps and the modal offer having a single step. ${ }^{20}$ Steps offer an average quantity of $34 \mathrm{MW}$ at an average price of USD 67/MWh, but sellers offer steps of up to $1000 \mathrm{MW}$ at prices of up to USD 300/MWh.

\section{(a) Prevalence of Congestion}

During the sample period - indeed, during the life of the power exchanges to date - congestion has been frequent and had a large impact on market prices. Table 2 summarizes the prevalence of congestion during the sample period by comparing the prices for each pair of regions, which differ only if the regions are separated by constrained links. Panel A shows the percentage of the hours over the sample period during which the price in the row region is higher than

\footnotetext{
${ }^{17}$ The Indian Energy Exchange allows piecewise-linear bids that are strict functions from price to quantity between up to 64 points. In practice, bidders almost always use these functions to closely approximate step functions (strictly correspondences) with constant quantities for a range of prices and then discrete increases in quantity over a single price tick. The difference between step functions and the linear interpolation of the exchange makes a trivial difference in clearing prices. I therefore assume bids have a step-function structure and apply the share-auction framework for modeling bids in terms of incremental quantities at each step (Wilson, 1979) (see Appendix A for details).

${ }^{18}$ During the study period, the system operator declared what the constraints were over the course of the day only if congestion occurred in any hour of the day in the unconstrained solution. On seven of 181 days in the sample, no congestion occurred, so the bootstrap simulations and counterfactual will assume that the market was unconstrained on these seven days.

${ }^{19}$ The price cap was lifted in October, 2009. Such a binding cap would invalidate the first-order approach to bidding optimality used in the estimation below. In May, 2010, the schedule of administrative prices for Unscheduled Interchange was revised. As the UI price schedule may influence the opportunity cost of buying and selling power in the day-ahead market, I truncate the sample before this regulatory change.

${ }^{20}$ This limited use of a complex strategy space occurs in other markets (Hortaçsu and Puller, 2008).
} 
the price in the column region. The most common patterns of congestion are for the North region or some combination of the South 1 and South 2 regions to be import constrained with respect to the central core of the East and West regions. The North region is constrained away from the Northeast, East and West regions over 18 percent of the time during this period. The South 1 region is import constrained with respect to this core 23 percent of the time and the South 2 region 26 percent of the time, as the link between the South 1 and South 2 regions also occasionally binds. Because constraints into the North and South tend to bind at different times, overall some constraint binds in 46 percent of the hours in the data (not shown in the table).

These binding constraints create large differences in market prices across regions. Table 2, Panel B shows the row region price less the column region price, conditional on the row region price exceeding the column region price. The average price difference between the North and East regions is USD 33.8/MWh, and between the South 1 and East regions USD 33.1/MWh, each about 38 percent of the mean unconstrained market-clearing price of USD 87.1/MWh. Appendix A (d) additionally shows that the amount of power flowing between regions is negatively correlated with differences in regional prices. Overall, it is clear that transmission congestion has very large effects on market prices in different regions of the grid.

\section{(b) Effect of Congestion on Market Concentration}

The fact that transmission constraints open up large differences in regional prices is consistent with either a competitive or an oligopolistic market. In a competitive market, or a power system with central dispatch based only on cost, tighter transmission constraints increase price differences by preventing least-cost dispatch across the whole grid, so that areas with high costs see high prices. In a strategic or oligopolistic market, additionally, suppliers will change their bids in response to tighter transmission constraints, which may exacerbate regional price differences relative to differences in cost, for example if import-constrained areas have very inelastic demand.

This subsection presents some reduced-form evidence, from market concentration and residual demand elasticities, that suppliers indeed face incentives to change their bidding behavior when transmission constraints bind. Figure 3 shows how the distribution of the Herfindahl-Hirschman Index (HHI) of market concentration changes when transmission con- 
straints bind. The HHI is based on sellers' offered volumes. The sample is restricted to hours in which the North Region is constrained from the rest of the grid (Panels A and C), or in which the South Region is constrained from the rest of the grid (Panels B and D). The HHI is then computed, using the same offered volumes, either only in the constrained region (North in Panel A, South in Panel B), or within the grid as a whole. Because this exercise uses micro-data on bids and constraints, the comparison is not between hours when the grid was constrained and hours when it was not, but between concentration when the grid was constrained and what concentration would have been, in the same hours with the same bids, had the grid not been constrained (i.e., if more transmission capacity was built).

The figure shows large increases in market concentrations when constraints bind. In the North Region, the modal HHI without constraints, in Panel A, is between 0.1 and 0.2 , and with constraints, in Panel $\mathrm{C}$, is between 0.4 and 0.5. Thus binding constraints cut the number of effective (equally-sized) firms from 5 to 10 to 2 to $3 .^{21}$ There are a number of hours with very high concentrations, above 0.5 , which are never observed when transmission constraints do not bind. The difference in concentration caused by transmission constraints in the South Region, comparing Panels B and D, is even greater, because the supply side in the South is very thin with relatively few participants.

The effect of market concentration, alone, on the incentive to exercise market power is ambiguous in this setting. In more concentrated markets, there are fewer bidders and therefore, at a given price, the slope of the residual demand curve of a supplier must be flatter. This slope effect tends to decrease the elasticity of residual demand and increase the incentive to raise prices. However, when the market is constrained, the residual demand curve shifts inwards by the quantity of imports or outward by the quantity of exports. The local market will clear at a different price point on the residual demand curve, at which quantity-price pair the residual demand may have a higher or lower elasticity. Because congestion induces both rotations and shifts of the residual demand curve, a seller in a constrained region does not necessarily face a lower elasticity of residual demand for the same bid.

Table 3 explores these effects for sellers in the North (Panel A) and South (Panel B) Regions facing import constraints. The table compares the elasticity of residual demand faced by the largest seller in each region, if they offered the same quantity (ninety percent of their

\footnotetext{
${ }^{21}$ Recall, an HHI of 1 indicates monopoly, 0.5 two equally sized firms, 0.20 five equal firms, etc.
} 
capacity), with transmission constraints either not binding (column 1) or binding (column 2). As with Figure 3, the sample for each panel is limited to hours in which the constraint actually did bind, so that the column 1 statistics are counterfactuals, without constraints, holding bids fixed. Each panel reports the median of three statistics: the HHI discussed above, the slope of the residual demand curve at the offered quantity, and the elasticity of the residual demand curve at the offered quantity. As noted above, the HHI increases by a factor of two or more when constraints bind, compared to the same hours unconstrained. The slope of residual demand also falls in magnitude, for example from $-22 \mathrm{MWh} / \mathrm{USD}$ to -15 MWh/USD in the North. This change in slope, and the shifts in residual demand from imports, combine to cut the residual demand elasticity from -8.60 to -3.15 , roughly a third the magnitude. Using a simple Lerner pricing rule, the mark-up over cost implied by an elasticity of -9 is $12.5 \%$, whereas that implied by an elasticity of -3 is $50 \%$, suggesting that constraints have a large effect on the incentive to exercise market power in the North Region. ${ }^{22}$ The South Region also sees falls in the magnitude of the slope and elasticity of residual demand when constraints bind. However, sellers in the South are small to begin with, with modest inframarginal quantities, and residual demand remains relatively elastic for the largest South seller even when the South Region is import constrained $\left(\varepsilon_{Q, P}=-12\right)$.

Comparing market structures and residual demand, it is therefore clear that at least some sellers have much stronger incentives to exercise market power when transmission constraints bind. These basic comparisons omit a couple important factors and on balance will probably understate differences in sellers' market power between a more- and less-constrained grid. First, we have only looked at incentives in the two most often import-constrained regions, when large sellers in export-constrained regions will also likely see lower residual demand elasticities when the grid is constrained. Second, the 'counterfactual' of an unconstrained grid does not allow bidders to change their behavior; in fact, the bids in constrained hours were submitted with some expectation that the grid might be constrained in those hours. If bidders had instead expected the grid to be unconstrained, they would have bid more aggressively. Therefore, these comparisons do not account for behavioral changes by market participants that would accentuate the mechanical differences in residual demand caused by transmission constraints.

\footnotetext{
${ }^{22} L=(P-C) / C=-\frac{1}{\varepsilon}=-\frac{1}{3} \Rightarrow P=(3 / 2) C$.
} 
In general, any reduced-form empirical approach will have difficulty estimating the effect of transmission constraints on market outcomes in this setting. Constraints bind endogenously in response to bids, and there is not a plausible instrument that exogenously shifts constraints and not other market conditions. The empirical approach is therefore to model the electricity market response to congestion under a variety of conduct assumptions, placing emphasis on strategic conduct based on the institutional evidence discussed above.

\section{Model of Supplier Bidding with Transmission Constraints}

To measure how transmission constraints affect market outcomes, I estimate firm costs and compute counterfactual market outcomes with different levels of transmission capacity. Under strategic conduct, firm costs are estimated from supply bid functions using a first-order approach accounting for the effect of transmission constraints on residual demand. ${ }^{23}$ The innovation in the methodology for cost estimation here is to account for the effect of transmission constraints on optimal bids.

\section{(a) Model of Optimal Bidding}

The model assumes that strategic firms submit supply functions to maximize expected profits. Firms face uncertainty over the bids of other firms and demand and submit their bids to the market one day ahead for each hour of the following day.

The offered supply of firm $i$ in region $g$ and time period $t$ in the day-ahead market is represented by a supply function $q_{i t}(p) .{ }^{24}$ The firm submits a supply function to maximize profits given the expected distribution of other firms' bids and demand, accounting for transmission constraints. The firm's problem is:

$$
\max _{\mathbf{b}_{\mathbf{i t}}, \mathbf{q}_{\mathbf{i t}}} \mathbb{E}_{\sigma_{-i t}}\left[q_{i t}(p) p-C_{i}\left(q_{i t}(p)\right)\right]
$$

where the supply function $q_{i t}(p)$ depends on the price $b_{i t k}$ and incremental quantity $q_{i t k}$ of

\footnotetext{
${ }^{23}$ This estimation approach, pioneered by Guerre, Perrigne and Vuong (2000), was first adapted for electricity markets by Wolak (2003) and has been used by Reguant (2014) to study complex bidding in the Spanish market and Allcott (2012) to study real-time pricing in the PJM market.

${ }^{24}$ This supply function is a continuous approximation to the step supply correspondence $\hat{q}_{i t}(p)=$ $\sum_{k} q_{i t k} \mathbf{1}\left\{b_{i t k}<p\right\}+\alpha q_{i t j} \mathbf{1}\left\{b_{i t j}=p\right\}$ for $\alpha \in[0,1]$. The firm supplies the incremental quantity $q_{i t k}$ at all prices strictly above $b_{i t k}$ and may offer any part $\alpha$ of an incremental quantity when the market price exactly equals the price of the bid tick, with the exact quantity supplied determined by market clearing.
} 
each bid tick $k$ and $C_{i}(\cdot)$ is $i$ 's cost of production. Note that there is no forward contract position in the profit expression, as there are no financial contracts tied to day-ahead market prices. The market clearing condition is that quantity supplied equal residual demand at the market-clearing price, $q_{i t}(p)=D_{i t}^{r g}\left(p \mid \sigma_{-i t}, \mathcal{L}_{t}\right)$, where $D_{i t}^{r g}\left(p \mid \sigma_{-i t}, \mathcal{L}_{t}\right)$ is the residual demand facing firm $i$ in region $g, \sigma_{-i t}$ are the strategies of bidders other than $i$, including demand bids and the competitive fringe, and $\mathcal{L}_{t}$ the set of transmission constraints.

Taking the derivative with respect to each bid-tick price, a necessary first-order condition for profit maximization is

$$
\left.\mathbb{E}_{\sigma_{-i t}}\left[\frac{\partial p}{\partial b_{i t k}}\left(q_{i t}(p)+\frac{\partial D_{i t}^{r g}\left(p \mid \sigma_{-i t}, \mathcal{L}_{t}\right)}{\partial p}\left(p-C_{i}^{\prime}\left(q_{i t}(p)\right)\right)\right)\right]\right|_{p=b_{i t k}}=0
$$

after substituting using both the market-clearing condition and the implicit function theorem (see Appendix B). This is equivalent to a Lerner pricing rule whereby the firm sets prices at marginal cost plus a markup given by quantity over a weighted expectation of the slope of residual demand. The weights $\partial p / \partial b_{i t k}$ are the slope of the market price in the bid tick price and have an economic interpretation as the probability that a given bid tick sets the market price, since with no smoothing this derivative is equal to one if a bid tick is marginal and zero otherwise. A greater slope of residual demand $\partial D_{i t}^{r g} / \partial p$ reduces the optimal markup at each quantity supplied.

The residual demand faced by each firm will depend on both the bids of other firms and the amount of transmission capacity. The residual demand facing firm $i$ in region $g$ is

$$
D_{i}^{r g}\left(p \mid \sigma_{-i t}, \mathcal{L}_{t}\right)=\sum_{j \neq i, j \in \mathcal{A}_{g}\left(p \mid \mathcal{L}_{t}\right)} q_{j}\left(p, \sigma_{j}\right)-\mathcal{F}\left(\mathcal{A}_{g} \mid p, \mathcal{L}_{t}\right)
$$

The residual demand that a bidder faces in their own region consists of demand and competing supply bids $q_{j}\left(p, \sigma_{j}\right)$ within the same constrained area, which are sensitive to price, and the fixed quantity that the region is importing, which is not sensitive to price at the margin, conditional on the set of binding constraints. I designate by $\mathcal{A}_{g}\left(p \mid \mathcal{L}_{t}\right)$ the set of regions to which region $g$ is connected by unconstrained transmission lines at a price $p$ and given line capacities $\mathcal{L}_{t}$, and call such a group of regions an area. These connections may be direct or indirect, through another region; all regions connected by any unconstrained path form an unconstrained area. As the price in $g$ rises, the region will tend to import more (attract net 
supply from other regions), which will induce transmission constraints to bind and tend to isolate $g$ in an area. (The area will also depend on the bids and prices in other regions, and thereby the net demands of those regions; I suppress this dependence in the area notation). This constrained area $\mathcal{A}_{g}\left(p \mid \mathcal{L}_{t}\right)$ is determined using the market-splitting algorithm described in Section 2. Let $\mathcal{F}\left(\mathcal{A}_{g} \mid p, \mathcal{L}_{t}\right)$ be the net constrained flows into area $\mathcal{A}_{g}$ at price $p$ and line capacities $\mathcal{L}_{t}$. This function gives the net supply of other regions, truncated by the available transmission capacity.

The derivative of the residual demand for this firm with respect to price is

$$
\frac{\partial D_{i t}^{r g}(p)}{\partial p}=\sum_{j \neq i, j \in \mathcal{A}_{g}\left(p \mid \mathcal{L}_{t}\right)} \frac{\partial q_{j t}\left(p, \sigma_{j}\right)}{\partial p}
$$

assuming that the constraints are not exactly binding, so that a small change in price does not change $\mathcal{A}_{g}\left(p \mid \mathcal{L}_{t}\right)$. Using this area assumes that bidders solve forward the congested area to which they will belong for possible realizations of other bids but do not change their bids to manipulate this area. (The assumption that constraints do not exactly bind for a given realization of demand and supply bids is innocuous, because the empirics will simulate uncertainty over others' bids so that all strategic bids are a best response to some probability of constraints binding.) If the set of binding constraints does not change, then constrained flows $\mathcal{F}(\cdot)$ are also fixed, so the second term in residual demand has a derivative of zero. The smaller is the constrained region $\mathcal{A}_{g}\left(p \mid \mathcal{L}_{t}\right)$, the weakly less negative is the residual demand slope bidder $i$ faces, as all bids outside of $\mathcal{A}_{g}$ contribute a fixed amount of imports or exports. The slope of residual demand for each bidder, for a given realization of demand and other supply bids, comes from only those bids with an open link to that bidder's region.

The overall effect of transmission constraints on supply bids will depend on the exact shape of the residual demand curve. Although the residual demand slope at a given price unambiguously falls when a region is constrained, the distribution of equilibrium prices in a region will change as constraints bind more often. A bidder may therefore expect bid ticks higher (lower) in the price distribution to be marginal if its region is import (export) constrained and will set markups based on the slope of residual demand in that range of prices, instead of in the range of prices anticipated without congestion. For example, a supplier in an import-constrained region may face more elastic demand at the high area- 
clearing prices expected to be marginal when constrained, inducing an expansion of quantity supplied. Conversely, a supplier in an import-constrained region gaining market share and serving greater inframarginal quantity would tend to increase markups.

\section{(b) Cournot Counterfactual}

In the counterfactual simulations I consider both competitive conduct, wherein bids are taken as cost and held fixed, and a Cournot model, wherein strategic bidders offer fixed quantities. The day-ahead market allows for bidding of price-quantity functions. Equilibria in supply functions, even without transmission constraints, are typically numerous and unstable (Holmberg, 2009; Baldick and Hogan, 2002), and there are additional computational difficulties in a constrained network (Wilson, 2008). Klemperer and Meyer (1989) show that the supply-function equilibria lie between competitive equilibrium and Cournot, wherein strategic sellers offer fixed quantities (i.e. inelastic supply functions).

Cournot models are widely used in empirical analysis of restructured electricity markets (Ito and Reguant, 2016; Bushnell, Mansur and Saravia, 2008; Puller, 2007; Neuhoff et al., 2005; Willems, 2002; Cardell, Hitt and Hogan, 1997). The Cournot model may be an especially good fit to the Indian market for two reasons. First, since firms use a small part of the strategy space in practice, with most bids having a single step, limiting firm strategies is preferable to limiting the number of firms, as a way of simplifying the model solution. Second, a relatively elastic demand side at the wholesale level leads to reliable price discovery in the model (as opposed to the common case of both electricity demand and supply being nearly inelastic, where the market price can vary wildly).

In the simulations I take all sellers in the North and West regions with greater than a one-percent share of total offered sell volume to be strategic and treat the other bidders as a competitive fringe. The market is not very concentrated overall; this set of 13 strategic firms covers 71 percent of all offered sell volume in the sample. I consider only strategic suppliers in the North and West regions because these regions are important in themselves, as large load and supply centers, respectively, and form relatively liquid markets when constrained, enabling a smooth approximation to the residual demand curve in each region. Not allowing other sellers, outside these thirteen, to adjust their bid functions will tend to understate the effect of transmission congestion on conduct and market outcomes. 
A Cournot equlibrium is a set of quantities for strategic firms $i$ such that they cannot profitably change quantity given their marginal costs $\gamma_{i}$, capacity constraints $\bar{q}_{i}$ and residual demand, where residual demand is composed of demand bids less the supply bids of fringe firms. Appendix B gives necessary and sufficient conditions for an equilibrium set of quantities and describes the solution algorithm.

An example of the solution to the model, unconstrained, is shown in Figure 2, Panel B, which shows the Cournot model simulation for the same hour for which Panel A, previously discussed, shows actual market clearance. In Panel B the increasing solid curve represents the marginal cost curve for strategic suppliers (author's estimates). The decreasing solid curve is the residual demand curve, composed of demand bids and fringe supply bids, and the dashedand-dotted line is a smoothed representation of the inverse residual demand. The vertical line is the equilibrium strategic quantity offered by the strategic suppliers, at which the equilibrium conditions are satisfied with respect to the smoothed inverse residual demand, as further expansion of quantity would steeply push down the market price. The marketclearing price for the simulation is the intersection of the strategic quantity with the actual, not smoothed, residual demand curve, and in this case matches exactly the actual clearing price in Panel A.

The above equilibrium applies to the realized residual demand curve faced by each seller within their own constrained area. The solution algorithm mimics the market splitting algorithm in order to determine what constrained area each seller is bidding within, first solving for the unconstrained solution with endogenous bids and then breaking off constrained areas and solving within each constrained area separately, shifting residual demand by the constrained level of imports or exports. ${ }^{25}$

\section{$5 \quad$ Estimation Strategy}

I apply the generalized method of moments (GMM) to the first-order conditions for optimal bids to estimate the marginal cost of electricity supply for firms over the quantity they offer

\footnotetext{
${ }^{25}$ The equilibrium in this model is not necessarily unique in theory, due to transmission constraints and the fact that I have not restricted the functional form of inverse residual demand to be concave. I explore this concern in Appendix B and do not find multiple equilibria in practice. The main reason is that the pattern of congestion for regions in the Indian grid is very one-sided: regions that are typically import constrained may not have the supply capacity, let alone the incentive, to congest the line going outwards, which could allow a different equilibrium.
} 
in the day-ahead market.

To approximate the uncertainty faced by suppliers I resample demand bids and the supply functions offered by other firms. Bids from all other bidders are drawn in complete days at the region-by-bidder-type level, where regions are the six regions in Figure 1, Panel B and the bidder types are State Generating Companies, Private Generating Companies, Distribution Companies and Industrial Firms. ${ }^{26}$ This resampling method is a block bootstrap which allows for arbitrary correlation among bids within region-bidder-day blocks. When there is a single bidder of a given type in a given region, this procedure maintains that bidder's identity, while when there are many bidders, such as industrial consumers on the demand side, it replicates the uncertainty caused by such firms dropping in and out of the market.

The estimation moments are the empirical analogue of the first-order condition (1):

$m_{i k h}\left(\gamma_{i}\right)=\frac{1}{|H(h)| S} \sum_{t \in H(h)} \sum_{s=1}^{S} \frac{\partial \tilde{p}^{s}}{\partial b_{i t k}}\left(\tilde{q}_{i t}\left(b_{i t k}\right)+\frac{\partial \tilde{D}_{i t}^{r g s}\left(b_{i t k} \mid \sigma_{-i}^{s}, \mathcal{L}_{t}\right)}{\partial p}\left(b_{i t k}-C_{i}^{\prime}\left(q_{i}\left(b_{i t k}\right)\right)\right)\right)$,

where $s \in\{1, \ldots, S\}$ are bootstrap iterations, $H(h)$ is the set of times with hour equal to $h$, and a tilde indicates a smoothed function. I take $S=100$. Every bootstrap draw of bids $\sigma_{-i}^{s}$ generates a residual demand curve that may differ both in its component parts and in the regions over which it is aggregated, depending on what transmission constraints the bids drawn induce to bind. The moments reflect uncertainty over the composition of one's own constrained area as well as others' bids. As bids are represented discretely, the derivative of residual demand, a key determinant of mark-ups, equals zero at almost all prices. I therefore smooth the residual demand function over prices with a normal kernel to approximate this derivative and the probability that a bid tick sets the market price (see Appendix B).

The parameters of interest are the marginal cost functions for each bidder. I specify $C_{i}(q)=\gamma_{i 0}+\gamma_{i} q$ so that marginal costs are constant at $\gamma_{i}$. Empirical papers on electricity markets have used a range of specifications for marginal cost suited to the question at hand. ${ }^{27}$ The assumption is that marginal cost is constant over the quantity offered in the day-ahead market. In support of this idea, the average sell bid described in Table 1 has less than two

\footnotetext{
${ }^{26}$ Other bidder-days are drawn with weights in proportion to a triweight kernel in number of days from the day for which uncertainty is being simulated, with a bandwidth of 14 days.

${ }^{27}$ Papers on vertical integration and transmission have used constant or piecewise constant marginal costs (Gans and Wolak, 2008; Neuhoff et al., 2005), whereas Reguant (2014) estimates linear marginal costs and adjustment costs to capture dynamic firm decision-making important for the study of complex bids.
} 
bid steps and only three strategic sellers average over three steps per offer. This means sellers do not bid as if their marginal costs have much slope and, practically, means there is little variation available in bids to estimate any changes in marginal cost with quantity.

I also estimate a capacity constraint for each seller as the maximum quantity offered by that seller in the market over the sample period. Sellers sometimes offering at their capacities in quantity does not invalidate the first-order conditions used in estimation, as the first-order conditions are with respect to price. All bid ticks are below the ceiling price, so bidders can always raise the price of their last unit of quantity, even if they cannot offer more quantity. The smoothing of residual demand using a normal kernel also ensures that all firms will have some non-zero demand elasticity, and therefore informative first-order conditions.

I estimate the marginal cost parameter $\gamma_{i}$ for each strategic seller by summing moments $\bar{m}_{i k o}\left(\gamma_{i}\right)=\sum_{h \in o} m_{i k o}\left(\gamma_{i}\right)$ over four equal hourly blocks $o$ and solving for the GMM estimator that minimizes the inner product of these moments

$$
\hat{\gamma}_{i}=\underset{\gamma}{\arg \min } \bar{m}_{i k o}\left(\gamma_{i}\right)^{\prime} \bar{m}_{i k o}\left(\gamma_{i}\right)
$$

One concern with this estimation strategy is that the residual demand a bidder faces may be endogenous with respect to econometric errors in their bid. For example, suppose a bidder has a positive cost shock for a given hour and this forces an offer at a high price, making a bidder marginal in a less elastic region of the demand curve. The estimation moment will infer from the low elasticity of demand that the bidder has a high mark-up and thus low cost, whereas the bidder actually was high cost because causality ran from bid to elasticity, and not vice versa. I therefore use temperature at the region-by-hour level from the day of bidding to instrument for the estimation moments in the main estimates.

Standard errors are bootstrapped to account for both statistical and simulation error. I bootstrap 100 samples, where each sample draws with replacement both days from the observed sample and simulated market outcomes, for each sampled day, from a set of 100 simulations of daily market outcomes. Cost coefficients are estimated for each set of days and market outcomes drawn. 


\section{Results}

\section{(a) Estimated Marginal Costs}

The characteristics and estimated marginal costs of strategic sellers are shown Table 4. There are four strategic sellers in the North and nine in the West. They are a heterogeneous lot, representing all of the four bidder types that bid on the exchange: state utilities, distribution companies (discoms), private generating companies and industrial plants. Column 3 of the table reports the market share of each strategic seller by their share of offered volume. The largest two sellers, including the largest single seller by a wide margin, at 23 percent market share, are state utilities in the Western region. ${ }^{28}$ Industrial plants have small shares of overall market volume but offer significant volume of up to $250 \mathrm{MW}$ in some hours. ${ }^{29}$ The largest suppliers in the North region are distribution companies, which the Electricity Act of 2003 permitted to vertically integrate into generation (Thakur et al., 2005).

The estimated marginal costs of these suppliers are presented in column 6. By seller type, the mean cost estimates in ascending order are USD 40.1/MWh for private generating companies, USD 61.5/MWh for industrial plants, USD 67.4/MWh for state utilities and USD 75.5/MWh for distribution companies. The range of cost estimates across sellers is broad. The estimated costs for individual sellers range from a low of USD 14.3/MWh up to a high of USD 121.1/MWh, with both extremes coming from industrial plants. The opportunity cost of supply in the day-ahead market is likely to be different from the pure technological cost of generation for industrial plants, which can alternately use the power themselves. Larger discoms and state utilities have estimated marginal costs in the narrower USD 50/MWh to USD 85/MWh range. ${ }^{30}$

Column (5) shows the mean quantity-weighted tick price of bids offered by each bidder, i.e. the average price at which a megawatt is offered. Comparing this column to the estimated costs implies that the average quantity-weighted markup of offered sell ticks is USD 8.5/MWh or 20 percent of marginal cost. Private generating companies have similar absolute markups

\footnotetext{
${ }^{28}$ There are 151 sellers that offer some quantity during the sample period, and the Herfindahl index for unconstrained offered volume by all sellers is 0.092 .

${ }^{29}$ Capacity of $200 \mathrm{MW}$ or more is high, but not unheard of, for a captive generation facility: India had 19 captive plants with above $100 \mathrm{MW}$ of capacity in 2004 (Central Electricity Authority, 2005).

${ }^{30}$ Table B5 in Appendix B compares these estimates, which use lagged temperature as an instrument, to estimates that use GMM without correcting for endogeneity. There are generally small differences in estimated costs by methodology. The remainder of the paper, including all counterfactuals, uses these Table 4 instrumental variable estimates.
} 
to other sellers, at USD 11/MWh, but lower costs and therefore larger markups in percentage terms. The estimated marginal costs reflect variation in underlying bids more than in margins (the correlation of estimated costs and weighted mean bid tick prices is 0.91). ${ }^{31}$

These cost estimates are consistent with the available information on generating costs in India. A limitation of the data is that the bidders are anonymous. The generation technology used by each seller is thus unknown and a precise comparison of estimated costs to physical costs is not possible. I therefore benchmark the cost estimates against public data on prices paid for power in the state sector (Central Electricity Regulatory Commission, 2011). The mean energy charges, meant to capture marginal costs, paid to state generating stations under long-term power purchase agreements in 2010, were USD 43.8/MWh for coal stations not at the pit-head, USD 43.9/MWh for natural gas units and USD 93.4/MWh for liquefied natural gas units. These are consistent with the costs I estimate, but for most fuels slightly lower, as the average estimated marginal cost across sellers is USD 63.3/MWh. It makes sense that marginal costs in the short-term market should be slightly higher than these benchmarks, since the state sector costs are for contracts of much greater quantities and longer durations and may rely on low-marginal-cost baseload plants.

From the estimation of marginal costs, a very high cost structure does not appear necessary to rationalize high market prices. Market prices have a mean of USD 87/MWh and a standard deviation of 49/MWh, and transmission constraints routinely create regional differences in price of USD 40/MWh or more. Yet these conditions do not imply, through the model estimates, that costs of supply are unreasonably high overall or in the constrained regions in particular. Cost estimates in this market are in line with energy charges paid to regulated public-sector plants. This leaves market structure, in the form of transmission constraints increasing market power, as a leading factor that may account for high prices in the shortterm market.

\footnotetext{
${ }^{31}$ Note it is possible to estimate costs above weighted mean offered tick price. For example, an industrial plant has bids averaging USD 37/MWh and costs of USD 45/MWh. This seller's average offers are only about half of the market-clearing price. The estimation weights ticks closer to the marginal price, which are more likely to be marginal, more highly, and therefore this seller's cost estimates are higher than its average bid, because the seller's higher bids are much more likely to be marginal.
} 


\section{(b) Counterfactual Model Fit}

Before turning to counterfactual outcomes it is important to understand the fit of the constrained Cournot model in the baseline case without any change in transmission capacity.

Table 5, Panel A, compares unconstrained market clearance with the bids actually submitted, in columns 1 and 2, with outcomes for the unconstrained Cournot model, in columns 3 and 4. I present the unconstrained clearance of the submitted bids for reference, but consider it an inappropriate benchmark for whether the model matches market conduct, because it runs unconstrained clearance using bids offered in a constrained environment. The model overpredicts unconstrained quantity, shown in Panel A, and therefore underpredicts unconstrained price by 13 percent (USD 11.5/MWh on a base of USD 87.1/MWh). In reality, when

firms bid, they know that they will face regional demand and be paid based on constrained, regional prices. This implies that an 'unconstrained' market, calculated by turning off transmission constraints but not changing bids, should have lower quantities than predicted by the model, as is observed.

Table 5, Panels B through D show that the model matches constrained market outcomesthat is, true market outcomes - extremely well, especially considering the parsimonious specification of costs. The North region is import constrained with respect to the West region 17 percent of hours in the model, as against 18 percent of hours in reality. The price difference between these regions conditional on the North price being greater is USD 28.2/MWh in the model and USD 33.7/MWh in the actual market clearance. The North region and West region have similar average net demands in the model as in the actual clearance, and these net demands are similarly variable. The fit in the South 1 region is also very good; for example, the difference between South 1 and West prices conditional on congestion is USD 32.9/MWh in fact and USD 39.5/MWh in the model.

\section{Counterfactual Transmission Expansion}

\section{(a) Simulated Benefits of Transmission Expansion}

I consider counterfactuals that vary in their assumption on market conduct as transmission capacity is built out. On the constraints themselves, I consider investments in new transmission capacity into the two most frequently constrained regions, the North and the South. The 
counterfactuals increase the transmission capacity from the East to the North and South 1 regions by increments up to $1200 \mathrm{MW} .^{32}$

Table 6 displays market outcomes with expanded transmission capacity. The panels of the table represent different physical counterfactuals, and the columns different assumptions on market conduct. Column 1 represents competitive market clearance with no transmission expansion. Column 2 assumes that suppliers have bid their cost curves in the data, and these cost curves are held fixed and a new market equilibrium found with a new level of transmission. Column 3 represents Cournot market clearance with no transmission expansion. Column 4 is Cournot conduct with fixed bids, where the quantities offered by strategic sellers in equilibrium are found at the baseline level of transmission, then held fixed as transmission expands. This scenario of sellers not responding to the grid is not meant to be realistic but to serve as a benchmark for the Cournot model with endogenous bids, of Column 5, where sellers do respond to new transmission and a new (constrained) market equilibrium is found at every level of counterfactual capacity. Each panel of the table shows how market prices, quantities and surplus change with the transmission expansion.

Panel A shows the response of the entire market to a marginal (400 MW) transmission expansion into the North region. This expansion reduces the share of constrained hours by approximately half, from 18 percent of hours to 11 percent in competitive scenarios (columns 1 and 2) and 17 percent to 8 percent in strategic scenarios (columns 3 and 5). The fall in congestion is smaller in the strategic scenario where sellers respond (column 5) than when they do not (column 4), because strategic sellers in importing regions tend to decrease supply as more imports are allowed. The difference in prices across regions conditional on congestion also falls, and the North region increases its regional net demand by drawing more power from the West.

The last three rows of Table 6, Panel A shows market surplus, divided into buyer's and seller's surplus. Note, regarding the baseline scenarios, that the surplus under competition (column 1) is smaller than under strategic scenarios (column 3). That surplus is higher under strategic behavior is counterintuitive and due to using different, model-consistent cost estimates in each case: in the competitive model, costs are assumed equal to bids, whereas in the strategic model, firms have mark-ups and so costs are estimated to be lower than

\footnotetext{
${ }^{32}$ Given that the East-to-West link has a high capacity, it makes a negligible difference whether the expansion into the constrained regions is from the East or the West.
} 
in the competitive model for the same bids. It is these lower cost estimates that increase the level of surplus in the strategic model, despite the exercise of market power. Moreover, because demand is typically very elastic near the market-clearing price, so that many buyers are roughly indifferent to buying, 66 percent of market surplus (column 3, =40.61/61.94) goes to the sell-side of the market. I take the baseline surplus under strategic conduct of column 3 as a common baseline for scaling surplus gains.

Under competition, surplus increases by a modest USD 1,070 per hour (column 2 less column 1), or 1.7 percent of the baseline strategic surplus of USD 61,940 per hour. Under strategic conduct with endogenous bids the gain in surplus is roughly twice as large for this marginal expansion, at USD 1,980 per hour or 3.2 percent of baseline surplus. This contrasts with basically no gain under a scenario that holds strategic bids fixed (column 4, USD 210 per hour). When bids are fixed, theoretically total surplus may still increase significantly, because power reaches higher-value buyers that were previously import-constrained, or is supplied by lower-cost sellers amongst the competitive fringe; for example, smaller industrial plants in the West can supply more power into the North region. In this scenario, however, buyer's surplus increases (column 4 less column 3) and seller's surplus falls by a nearly equal amount. Thus the effect of the transmission expansion, without changes in strategic supply, is to lower prices in the import-constrained region, transferring surplus from one side of the market to the other. The primary gains from this expansion, observed in the Cournot scenario with endogenous bids, are thus due to a strategic increase of supply in response to the availability of greater transmission capacity.

The gains from expansions are greater and the differences between competitive and strategic scenarios starker in the South region. Panels B and C consider marginal (400 MW) and large (1200 MW) increases, respectively, of transmission capacity into the South 1 region. The marginal increase cuts congestion from about 30 percent (columns 1 and 3) to about 10 percent (Panel B, columns 2 and 5) under all conduct assumptions, and the large increase in transmission is enough to basically end congestion (Panel C, columns 2 and 5). Under the competitive scenario, the large increase in capacity causes some increase in South region net demand and West region net supply, and gains of up to 6.0 percent of baseline market surplus (Panel C, column 2, = (40.88-37.16)/61.94), accruing to both sides of the market. Under the strategic scenario, the gains for a large increase in capacity are more than twice as large, at 
13.3 percent $($ column $5,=(70.18-61.94) / 61.94)$ of baseline surplus. The strategic expansion of transmission capacity into the South 1 region increases net demand in that region by 100 MW per hour (column 5 less 3, Panel C), over all constrained and unconstrained hours, much of which is due to increased net supply from the West region (Note in column 5 the South 1 region is importing more but just barely a net buyer, as it is the only region that can wheel power into high-demand South 2). Surplus gains from South region expansion accrue more to buyers than to sellers; the effect is of opening up an import-constrained region with high demand but little indigenous supply. Note, by comparison with column 4, that the gains in the strategic scenario are due to increases in supply and not just a reallocation of demand to high-value South 1 buyers. The surplus gains in the column 4, fixed bid scenario are about one-third as large.

Figure 4 summarizes the surplus gains for these counterfactual increases of transmission capacity. Panel A shows expansions of capacity into the North region and Panel B into the South region. In each panel, the solid (black) line represents surplus holding strategic bids fixed at the baseline level, the dashed (blue) line surplus with competitive bids and the dotted (red) line surplus with endogenous strategic bids. Each surplus measure is scaled by subtracting the baseline market surplus under that scenario and dividing by the baseline surplus under strategic conduct. The Table 6 scenarios for the North and South are traced out for a range of capacities. There are three conclusions from the figure. First, the surplus gains are largest in strategic bid scenarios, topping out at 5.6 percent of surplus in the North, 13.3 percent in the South and 18.9 percent in total. This is a substantial gain from relieving congestion, of USD 11,720 per hour or USD 103 million per year (USD 31m in the North, USD 72m in the South). The ratio of the aggregate welfare gain from both expansions (done independently) with endogenous strategic bids to the gain with fixed bids is 4.5; i.e., the strategic response to the expansions accounts for 81 percent of their welfare benefit. Second, marginal gross returns to investment are diminishing, though much more so in the North, where gains level off after the first 400 MW expansion, than the South, where there are significant gains up through 1200 MW. Third, the relative gains from transmission expansion under competitive market conduct depend on the expansion considered. For the North region, strategic counterfactuals show greater gains in surplus, but competitive counterfactuals converge to show very similar gains at higher levels of transmission expansion. By contrast, in the South, strategic 
counterfactuals dominate competitive ones with respect to surplus gains at all capacities.

Who gains from these investments? Figure 5 divides the gains in surplus across importing and exporting regions and the buy and sell sides of the market. Panel A shows surplus gains from a $400 \mathrm{MW}$ transmission expansion into the North region and Panel B a like expansion into the South region. In each panel, the three bars grouped on the left represent changes in surplus for buyers (grey), sellers (light grey) and both sides together (black) in the importing region, while the three bars on the right represent changes for the exporting region. In the North region, in Panel A, the losses to sellers (light grey, left group), who lose market power as import capacity grows, outweigh the gains to buyers from lower prices (grey bar, left group), so the net surplus change in the region is slightly negative. That is, the highly importconstrained North region would in sum prefer that the constraint not be relaxed. This small net loss in surplus is offset by large gains to sellers in the exporting regions, which benefit from higher prices and quantity after they are integrated with the high-demand North (light

grey, right group). The pattern of gains for an import expansion into the South region, in Panel B, is similar, though in this case the gains to buyers within the South (5.2 percent of baseline surplus) outweigh the losses to sellers from being undercut (2.2 percent). Thus most of the surplus gains from new transmission accrue in exporting regions, whose sellers are able to supply more and at higher prices. Overall, importing regions have modest net gains in surplus because undercutting sellers' market power and hence surplus offsets gains to the buy side from lower prices and greater quantity. The gains to transmission expansion accrue mainly to lower-cost sellers that can serve new export markets.

\section{(b) Costs of Infrastructure for Transmission Expansion}

The above estimate of social benefits, or increased surplus, from transmission expansion is not comprehensive, as it does not account for the costs of building the needed infrastructure. The socially optimal level of infrastructure investment will generally leave some congestion, for if one built the transmission capacity needed to eliminate every last hour of congestion, there would be no price differences across regions and the marginal benefit of transmission capacity would be zero. To estimate the net change in surplus from transmission expansion I therefore develop a measure of the costs of marginal transmission capacity to compare to the above measure of benefits. 
The method of estimating marginal expansion costs has three steps. First, I identify the physical lines that form binding constraints on inter-regional flow during my study period. Second, I use planning documents to ascertain what more would have had to be built to relieve these constraints. Because elements of the grid such as transmission lines and substations are interdependent, the marginal investment required to relieve constraints is above the replacement cost of the constrained grid links. Third, I use regulatory rulings on the costs of existing grid elements to estimate the cost of the marginal expansion proposed. The transmission system is regulated under a cost-plus regulatory regime so the regulator commonly rules on the cost of grid elements similar to those needed for the expansion in the determination of transmission tariffs. ${ }^{33}$

Table 7, using this method, summarizes the annualized costs and benefits of marginal (400 MW) expansions in transmission capacity on the East-to-North and East-to-South links. ${ }^{34}$ The table shows the annual cost of constructing the needed grid elements to expand transmission capacity between regions and the ratio of the gains in market surplus to those costs. I find that marginal transmission expansion on these links would have benefit-cost ratios of 1.65 and 3.24, respectively, both well above one, the ex post break-even level of social returns. These proposed marginal investments have a much higher social return than the 16 percent private return on equity, i.e. a benefit-cost ratio of 1.16 , allowed by the regulator for investment in transmission capacity. Moreover, as the marginal benefits for transmission expansion to the South region, shown in Figure 4, Panel B, flatten out only gradually, additional expansion of this link would also yield benefits exceeding costs by a large amount. Further capacity past $400 \mathrm{MW}$ into the North region, by contrast, would add little to social surplus. ${ }^{35}$ With

\footnotetext{
${ }^{33}$ The estimation of costs can be illustrated with the example of an expansion of the capacity from the East Region to the North Region. The system operator stated, in monthly reports on available transmission capacity, that a transmission link between Farakka and Malda was the constraint on congestion across these regions (Power Grid Corporation of India Limited, 2009). The system operator has developed a plan to circumvent this constraint by building an additional high-voltage line from Rajarhat, near Kolkata, to Purnea along with associated infrastructure (National Load Dispatch Centre, 2012). I take the cost of the planned grid elements from recent regulatory filings for comparable expansions and apply the costs of these elements to the expansion plan (Central Electricity Regulatory Commission, 2012a). Costs include depreciation, interest and operations and maintenance expenses and are presented on an annual, amortized basis. I exclude the regulated return on equity, which is not a social cost, from cost calculations.

${ }^{34}$ Transmission capacity is typically measured in units of potential (kilovolts); I assume $1 \mathrm{kV}$ of line can transmit 1.25 MW of energy to express capacities in energy terms instead.

${ }^{35}$ Holding the marginal cost of expansion constant from $400 \mathrm{MW}$ to $1200 \mathrm{MW}$ of capacity and using the surplus generated by this larger expansion, the ratio of benefits to costs for investments in East-North and East-South are 0.96 and 1.73, respectively. These estimates should be taken with caution, as the assumption of constant marginal costs of transmission expansion on these links is likely to be poor. The marginal cost curve for transmission investment slopes up as new lines have worse locations, longer runs and more complex tie-ins with the existing grid. Central Electricity Regulatory Commission (2012a) Petitions No. 12/2002 and
} 
the same cost measure but using net gains under counterfactual competitive conduct, the case for a $400 \mathrm{MW}$ transmission investment is marginal. The ratios of benefits to costs under competition for expansions into the North and South regions are 0.88 and 0.86 , respectively.

\section{(c) Interpretation of Net Surplus Gains}

The comparisons above rely on several broad assumptions that, on balance, probably understate the benefits of transmission investment.

First, I do not model the contract market and omit any potential gains from trade in that market from my counterfactuals. However, the contract market appears to be fairly well linked to the day-ahead market, and in 22 percent of constrained hours into the South and 37 percent into the North, no transmission capacity $(0 \mathrm{MW})$ is available for the day-ahead market. When capacity runs out, this implies that all the capacity has been booked in the earlier contract market, which would also have been constrained and may then have directly benefited from transmission expansions. Moreover, if relaxing transmission constraints caused buyers and sellers to shift trade out of the bilateral contract market, which is currently favored in the transmission allocation process, and into the day-ahead market, there may be further gains from increased market liquidity and efficiency (Mansur and White, 2012).

Second, surplus is based on wholesale bids including bids from distribution companies. These distribution companies are state agents bidding on behalf of retail customers, and I take the valuations in their wholesale bids as the social value of that electricity. Given the distorted state of retail supply in India, this assumption could either overstate or understate surplus depending on what customers are being rationed at the margin and who might be supplied the additional power procured. Urban consumers cut-off by discoms often run generators at a marginal cost of supply 50 percent or 100 percent above the wholesale market price, yet rural and agricultural consumers face marginal prices far below cost or no marginal price at all. Thus, observing only the wholesale bidding data and not who receives the power, it is not possible to say whether wholesale valuations are too high or too low, relative to retail valuations. From ongoing research with distribution companies in several Indian states, I consider it more likely that the marginal rationed consumer in most cases lives in a town or urban area, so that wholesale valuations are too low; however, I am not aware of any research escalated with each recent investment. 
that estimates the effect of wholesale market outcomes on distribution-level rationing.

Third, I treat only a subset of thirteen large sellers as strategic and hold the bids of all nonstrategic sellers fixed. This assumption tends to understate the changes in market outcomes under transmission expansion, to the extent that fringe sellers would also have changed their behavior in an unconstrained market. Against this force, in counterfactuals relying on the Cournot model, strategic suppliers are assumed to bid inelastic supply functions, which tends to produce greater changes in bids than if other strategic parties bid partly elastic supply functions.

Fourth, gains during the sample period and investment costs are annualized and assumed constant over time. The benefits of capacity expansion assume no growth in the day-ahead market and no long-term benefits from transmission expansion in terms of better locational choices of new power plants, on the supply side, or industrial plants, on the demand side. There may be substantial long-term benefits from transmission lowering generation costs if it reduces the need for supply to co-locate with demand. Transmission also increases grid reliability and redundancy, which offer economic benefits through physical insurance against system outages. ${ }^{36}$

\section{Conclusion}

I study the potential benefits of greater integration in the Indian electricity market. The main finding of the paper is that the surplus gains from building transmission to integrate the country's electricity market are large and mostly due to the competitive effects of such transmission on the supply offered by strategic firms. Counterfactual increases of transmission capacity into the most congested regions of the grid increase market surplus by 19 percent and accrue mainly to sellers in exporting regions that can increase supply to high-demand

\footnotetext{
${ }^{36}$ The largest blackout in history, which brought down the Northern Indian grid for two days in late July, 2012, cutting off power to states with a population of 670 million, was not due to excessive demand, as widely reported in the press (Yardley and Harris, July 31, 2012), but a transmission problem. The period in July when the blackout occurred had relatively low aggregate demand since the monsoon had begun, and the grid frequency, a summary statistic for net demand on the grid, was very close to the nominal frequency of 50 $\mathrm{Hz}$ at the time, indicating that there was no net over-drawal on the grid. However, a large amount of power was being exported from the West region to the North and the reliability margin on this line had been set too low, given that a major transmission corridor was down for maintenance. Moreover, the balancing price mechanism, based on the common frequency in all regions of the syncronized grid, gave a common price in the North and West regions, and thus did not reflect this transmission constraint. This mis-pricing caused real-time over-injections in the West region and over-drawals in the North region, producing power flows that exceeded the line capacity and triggered a cascading series of failures in the entire Northern-Eastern-Western grid (Central Electricity Regulatory Commission, 2012b).
} 
areas. I calculate, by comparison with counterfactuals where sellers cannot respond to the new transmission lines, that 81 percent of this welfare gain is due to transmission mitigating market power. The returns from investing in transmission infrastructure are positive if firms are assumed to behave strategically, but near zero if firms are competitive and so do not respond to the newly integrated grid.

A natural question is why these lines, with positive social returns, have not already been built. One answer is that, given the rapid change in the Indian electricity sector, it is hard to anticipate the value of infrastructure in a new power market. In this view, the congestion here is a costly but temporary disequilibrium to be remedied as the government continues to expand transmission capacity (Central Electricity Authority, 2012a). This answer does not seem entirely satisfying, since the patterns of transmission constraints studied here are fairly long-lived; for example, the North Region import constraint is binding about as frequently, and the South Region import constraint was binding even more frequently, in data from 2014, than in the study sample four years earlier. Another answer is that transmission planners are not accounting for the competitive effects of transmission. The returns to transmission investment are set by cost-plus regulation, so merchant transmission projects earn a fixed rate of return on investments deemed useful, which does not vary based on the potential gains from trade or price differences across the regions a project will connect. They do not account, in particular, for whether a line may be critical to inter-regional competition.

To my knowledge this is the first econometric study of a wholesale power market in a developing country. There is an extensive literature on deregulated electricity markets in developed-country markets around the world, showing that the exercise of market power affects productive efficiency, but not allocative efficiency (Joskow, 2008; Borenstein, Bushnell and Wolak, 2002). When a generator withholds capacity that would be competitive to operate, in order to raise prices, less efficient plants are called to make up the gap, and consumers are served in any case. Market power is less studied but potentially more important for welfare in developing countries. In India's market, where the demand side is often rationing power at the retail level, withholding power may instead increase demand not met, from any source. Scarce and unreliable power supply reduces the productivity of firms (Allcott, Collard-Wexler and O'Connell, 2014; Fisher-Vanden, Mansur and Wang, 2012) and surely harms consumers as well. An important direction for research is therefore to better understand the pass-through 
of wholesale market outcomes to distribution-level power supply and power rationing.

\section{References}

Allcott, Hunt. 2012. "The Smart Grid, Entry, and Imperfect Competition in Electricity Markets." National Bureau of Economic Research Working Paper \#18071.

Allcott, Hunt, Allan Collard-Wexler, and Stephen D. O'Connell. 2014. "How Do Electricity Shortages Affect Productivity? Evidence from India." National Bureau of Economic Research Working Paper \#1997\%.

Bacon, R. W., and J. Besant-Jones. 2001. "Global Electric Power Reform, Privatization, and Liberalization of the Electric Power Industry in Developing Countries 1." Annual Review of Energy and the Environment, 26(1): 331-359.

Baldick, Ross, and William Hogan. 2002. "Capacity Constrained Supply Function Equilibrium Models of Electricity Markets: Stability, Non-decreasing constraints, and Function Space Iterations." UCEI Working Paper, PWP-089.

Banerjee, Abhijit, Esther Duflo, and Nancy Qian. 2012. "On the Road: Access to Transportation Infrastructure and Economic Growth in China." National Bureau of Economic Research Working Paper \#17897.

Benjaming F. Hobbs, Carolyn B. Betzler, and Jong-Shi Pang. 2000. "Strategic gaming analysis for electric power systems: An MPEC approach." IEEE Transactions on Power Systems, 15(2): 638-645.

Bhattacharya, Saugata, and Urjit R. Patel. 2008. "The Power Sector in India: An Inquiry into the Efficacy of the Reform Process." In India Policy Forum. Vol. 4, , ed. Suman Bery, Barry Bosworth and Arvind Panagariya, Chapter 5, 211-260. National Council of Applied Economic Research, New Delhi.

Borenstein, Severin, James B. Bushnell, and Frank A. Wolak. 2002. "Measuring Market Inefficiencies in Californias Restructured Wholesale Electricity Market." The American Economic Review, 92(5): 1376-1405. 
Borenstein, Severin, James B. Bushnell, and Steven Stoft. 2000. "The competitive effects of transmission capacity in a deregulated electricity industry." The Rand Journal of Economics, 31(2): 294-325.

Bushnell, James B., Erin T. Mansur, and Celeste Saravia. 2008. "Vertical arrangements, market structure, and competition: an analysis of restructured US electricity markets." The American Economic Review, 98(1): 237-266.

Cardell, Judith B., Carrie Cullen Hitt, and William H. Hogan. 1997. "Market power and strategic interaction in electricity networks." Resource and Energy Economics, 19(1): 109-137.

Central Electricity Authority. 2005. "General Review 2003-2004." Central Electricity Authority, Ministry of Power.

Central Electricity Authority. 2011a. "Growth of Electricity Sector in India from 19472011." Central Electricity Authority, Ministry of Power.

Central Electricity Authority. 2011b. "Load Generation Balance Report." Central Electricity Authority, Ministry of Power.

Central Electricity Authority. 2011c. "Operation Performance of Generating Stations in the Country During the Year 2010-11." Central Electricity Authority, Ministry of Power.

Central Electricity Authority. 2012a. "Draft National Electricity Plan - Transmission." Central Electricity Authority, Ministry of Power.

Central Electricity Authority. 2012b. "National Electricity Plan." Central Electricity Authority, Ministry of Power.

Central Electricity Regulatory Commission. 2008a. "Central Electricity Regulatory Commission (Open Access in Inter-State Transmission) Regulations, 2008." No. L7/105(121)/2007-CERC.

Central Electricity Regulatory Commission. 2008b. "Statement of Reasons in Support of Amendment to the Central Electricity Regulatory Commission (Open Access in InterState Transmission) Regulations, 2004." 
Central Electricity Regulatory Commission. 2009. "Central Electricity Regulatory Commission (Unscheduled Interchange Charges and Related Matters) Regulations, 2009." No.L-1(1)/2009-CERC.

Central Electricity Regulatory Commission. 2011. "Report on Short-term Power Market in India, 2010-11."

Central Electricity Regulatory Commission. 2012a. "Orders." Available at http://cercind.gov.in/orders.html.

Central Electricity Regulatory Commission. 2012b. "Report on the Grid Disturbances of 30th July and 31st July 2012." Available at http://www.cercind.gov.in/2012/orders/Final_Report_Grid_Disturbance.pdf.

Davis, Lucas, and Catherine Hausman. 2014. "The Value of Transmission in Electricity Markets: Evidence from a Nuclear Plant Closure." National Bureau of Economic Research Working Paper \#20186.

Dinkleman, Taryn. 2011. "The Effects of Rural Electrification on Employment: New Evidence from South Africa." American Economic Review, 101(7): 3078-3108.

Dirkse, Steven P., and Michael C. Ferris. 1995. "The path solver: a nommonotone stabilization scheme for mixed complementarity problems." Optimization Methods and Software, 5(2): $123-156$.

Donaldson, David. 2012. "Railroads of the Raj: Estimating the Impact of Transportation Infrastructure." American Economic Review, forthcoming.

Donaldson, David, and Richard Hornbeck. 2013. "Railroads and American Economic Growth: A Market Access Approach." NBER Working Paper \#19213.

Economist. 2012. "Energy in India: The Future is Black."

Faber, Benjamin. 2014. "Trade Integration, Market Size and Industrialization: Evidence from China's National Trunk Highway System." Review of Economic Studies, 81(3): 10461070 . 
Fisher-Vanden, Karen, Erin T. Mansur, and Qiong (Juliana) Wang. 2012. "Costly Blackouts? Measuring Productivity and Environmental Effects of Electricity Shortages." National Bureau of Economic Research Working Paper \#17r41.

Gans, Joshua, and Frank A. Wolak. 2008. "A Comparison of Ex Ante Versus Ex Post Vertical Market Supply: Evidence from the Electricity Supply Industry." Mimeo, Stanford University.

Guerre, Emmanuel, Isabelle Perrigne, and Quang Vuong. 2000. "Optimal Nonparametric Estimation of First-price Auctions." Econometrica, 68(3): 525-574.

Holmberg, Pär. 2009. "Numerical calculation of an asymmetric supply function equilibrium with capacity constraints." European Journal of Operational Research, 199(1): 285-295.

Hortaçsu, Ali, and Steven L. Puller. 2008. "Understanding strategic bidding in multiunit auctions: A case study of the Texas electricity spot market." The RAND Journal of Economics, 39(1): 86-114.

Indian Energy Exchange. 2014. "Indian Power Market: Journey So Far and Way Forward." Indian Energy Exchange.

International Energy Agency. 2011. "World Energy Outlook."

Ito, Koichiro, and Mar Reguant. 2016. "Sequential Markets, Market Power and Arbitrage." American Economic Review, 106(7): 1921-1957.

Jamasb, Tooraj. 2005. Electricity sector reform in developing countries: A survey of empirical evidence on determinants and performance. Vol. 3549, World Bank Publications.

Jensen, Robert. 2007. "The digital provide: Information (technology), market performance, and welfare in the South Indian fisheries sector." The Quarterly Journal of Economics, 122(3): 879-924.

Joskow, Paul L. 2008. "Lessons learned from electricity market liberalization." The Energy Journal, 29(2): 9-42.

Joskow, Paul L., and Jean Tirole. 2000. "Transmission rights and market power on electric power networks." The Rand Journal of Economics, 450-487. 
Kastl, Jakub. 2012. "On the Properties of Equilibria in Private Value Divisible Good Auctions with Constrained Bidding." Journal of Mathematical Economics, 48(6): 339-352.

Klemperer, Paul D, and Margaret A Meyer. 1989. "Supply function equilibria in oligopoly under uncertainty." Econometrica: Journal of the Econometric Society, 12431277.

Kolstad, Charles D., and Lars Mathiesen. 1987. "Necessary and sufficient conditions for uniqueness of a Cournot equilibrium." The Review of Economic Studies, 54(4): 681-690.

Kolstad, Charles D., and Lars Mathiesen. 1991. "Computing Cournot-Nash Equilibria." Operations Research, 739-748.

Lipscomb, Molly, A. Mushfiq Mobarak, and Tania Barham. 2013. "Development Effects of Electrification: Evidence from the Topographic Placement of Hydropower Plants in Brazil." American Economic Journal: Applied Economics, 5(2): 200-231.

Malik, Kabir, Maureen Cropper, Alexander Limonov, and Anoop Singh. 2011. "Estimating the Impact of Restructuring on Electricity Generation Efficiency: The Case of the Indian Thermal Power Sector." National Bureau of Economic Research Working Paper \#17383.

Mansur, Erin T., and Matthew White. 2012. "Market Organization and Efficiency in Electricity Markets." Mimeo, Dartmouth College.

McRae, Shaun. 2014. "Infrastructure Quality and the Subsidy Trap." American Economic Review, forthcoming.

Meeus, Leonardo, Karolien Verhaegen, and Ronnie Belmans. 2009. "Block order restrictions in combinatorial electric energy auctions." European journal of operational research, 196(3): 1202-1206.

Monitoring Analytics. 2011. "State of the Market Report for PJM, 2010." Monitoring Analytics, LLC.

Nag, Tirthankar. 2010. "Captive Generation Capacity in India: The Dilemma of Dualism." In India Infrastructure Report. Oxford University Press. 
National Load Dispatch Centre. 2012. "Operational Feedback on Transmission Constraints."

Neuhoff, Karsten, Julian Barquin, Maroeska G. Boots, Andreas Ehrenmann, Benjamin F. Hobbs, Fieke A. M. Rijkers, and Miguel Vazquez. 2005. "Networkconstrained Cournot models of liberalized electricity markets: the devil is in the details." Energy Economics, 27(3): 495-525.

Power Grid Corporation of India Limited. 2009. "Available Transfer Capacity of Eastern Region [Various Months]."

Puller, Steven L. 2007. "Pricing and firm conduct in California's deregulated electricity market." The Review of Economics and Statistics, 89(1): 75-87.

Reguant, Mar. 2014. "Complementary Bidding Mechanisms and Startup Costs in Electricity Markets." Review of Economic Studies, forthcoming.

Sharma, Anil K., and Ashutosh Vashishtha. 2007. "Weather derivatives: risk-hedging prospects for agriculture and power sectors in India." Journal of Risk Finance, 8(2): 112132.

Thakur, Tripta, S. G. Deshmukh, S. C. Kaushik, and Mukul Kulshrestha. 2005. "Impact assessment of the Electricity Act 2003 on the Indian power sector." Energy Policy, 33(9): 1187-1198.

Willems, Bert. 2002. "Modeling Cournot competition in an electricity market with transmission constraints." The Energy Journal, 23(3): 95-126.

Williams, J. H., and R. Ghanadan. 2006. "Electricity reform in developing and transition countries: A reappraisal." Energy, 31(6): 815-844.

Wilson, Robert. 1979. "Auctions of shares." The Quarterly Journal of Economics, 675-689.

Wilson, Robert. 2008. "Supply function equilibrium in a constrained transmission system." Operations research, 56(2): 369-382.

Wolak, Frank A. 2003. "Identification and Estimation of Cost Functions Using Observed Bid Data: An Application to Competitive Electricity Markets." In Advances in Economics 
and Econometrics: Theory and Applications, Eighth World Congress. Vol. 2, , ed. Lars Peter Hansen Mathias Dewatripont and Stephen J. Turnovsky, 133-169. Cambridge University Press.

Wolak, Frank A. 2007. "Quantifying the supply-side benefits from forward contracting in wholesale electricity markets." Journal of Applied Econometrics, 22(7): 1179-1209.

Wolak, Frank A. 2008. "Reforming the Indian Electricity Supply Industry." In Sustaining India's Growth Miracle. , ed. Jagdish N. Bhagwati and Charles W. Calomiris, 115-155. Columbia Business School.

Wolak, Frank A. 2012. "Measuring the Competitiveness Benefits of a Transmission Investment Policy: The Case of the Alberta Electricity Market." Mimeo, Stanford University.

Wolfram, Catherine D. 1999. "Measuring duopoly power in the British electricity spot market." American Economic Review, 89(4): 805-826.

Xu, Lin, and Ross Baldick. 2007. "Transmission-constrained residual demand derivative in electricity markets." Power Systems, IEEE Transactions on, 22(4): 1563-1573.

Yardley, Jim, and Gardiner Harris. July 31, 2012. "2nd Day of Power Failures Cripples Wide Swath of India." The New York Times.

Zhang, Yin-Fang, David Parker, and Colin Kirkpatrick. 2008. "Electricity sector reform in developing countries: an econometric assessment of the effects of privatization, competition and regulation." Journal of Regulatory Economics, 33(2): 159-178. 


\section{$9 \quad$ Figures}

Figure 1: Indian Power Grid

A. Power Exchange Bidding Areas

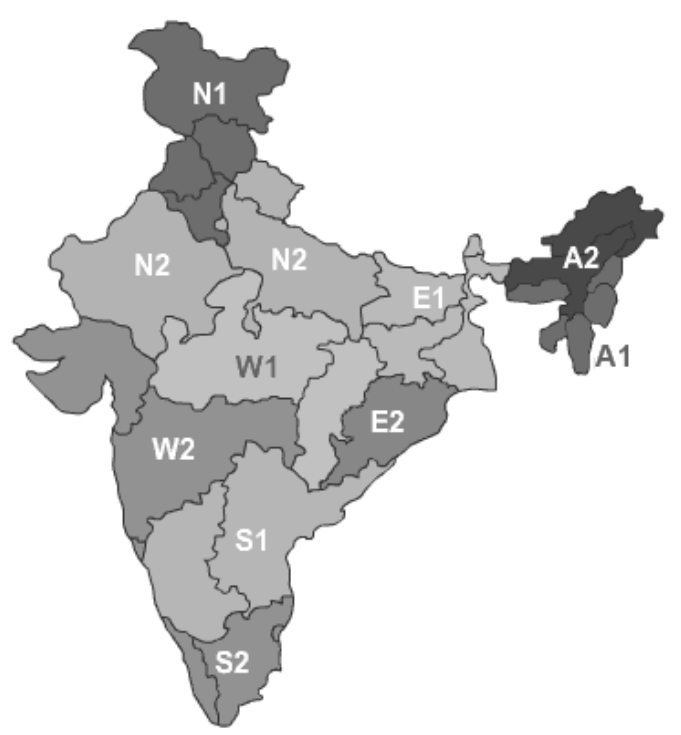

B. Schematic of Ever-constrained Regions

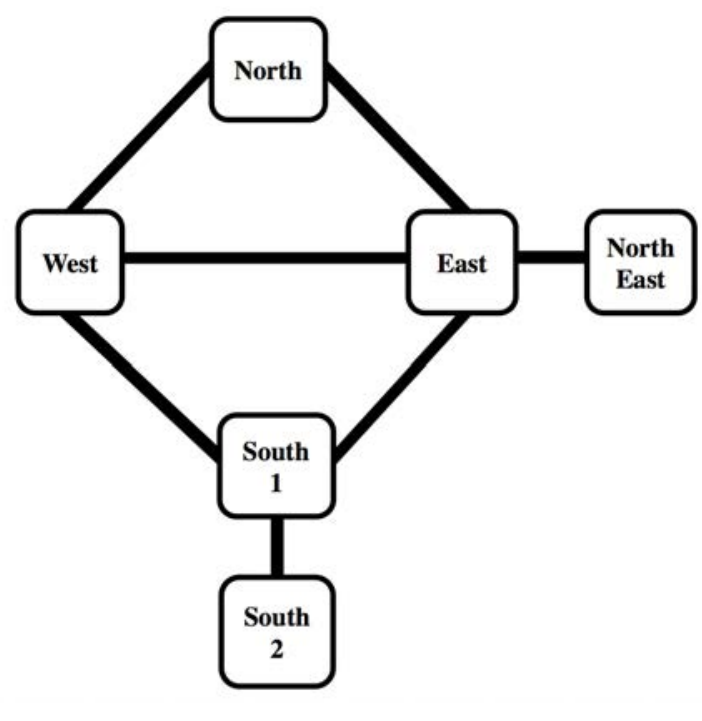

The figure shows geographic and schematic representations of the bidding areas in the Indian day-ahead power market. Panel A represents the ten subregions in which bids are submitted, formed from five regions with two subregions apiece. Panel B represents the six functionally distinct regions that are ever separated by constrained transmission links and the structure of interregional transmission links amongst them. 
Figure 2: Unconstrained Market Clearance

January 26th, 2010, hour 17

A. Actual market clearance

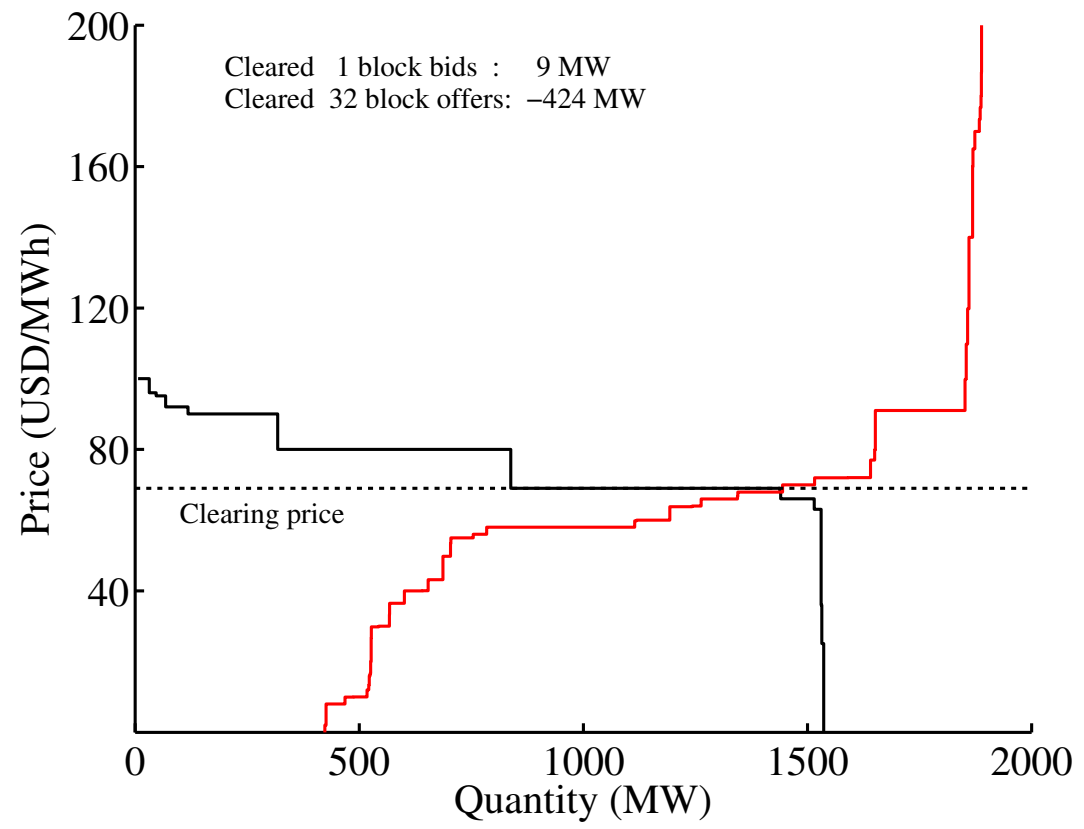

B. Cournot model simulation

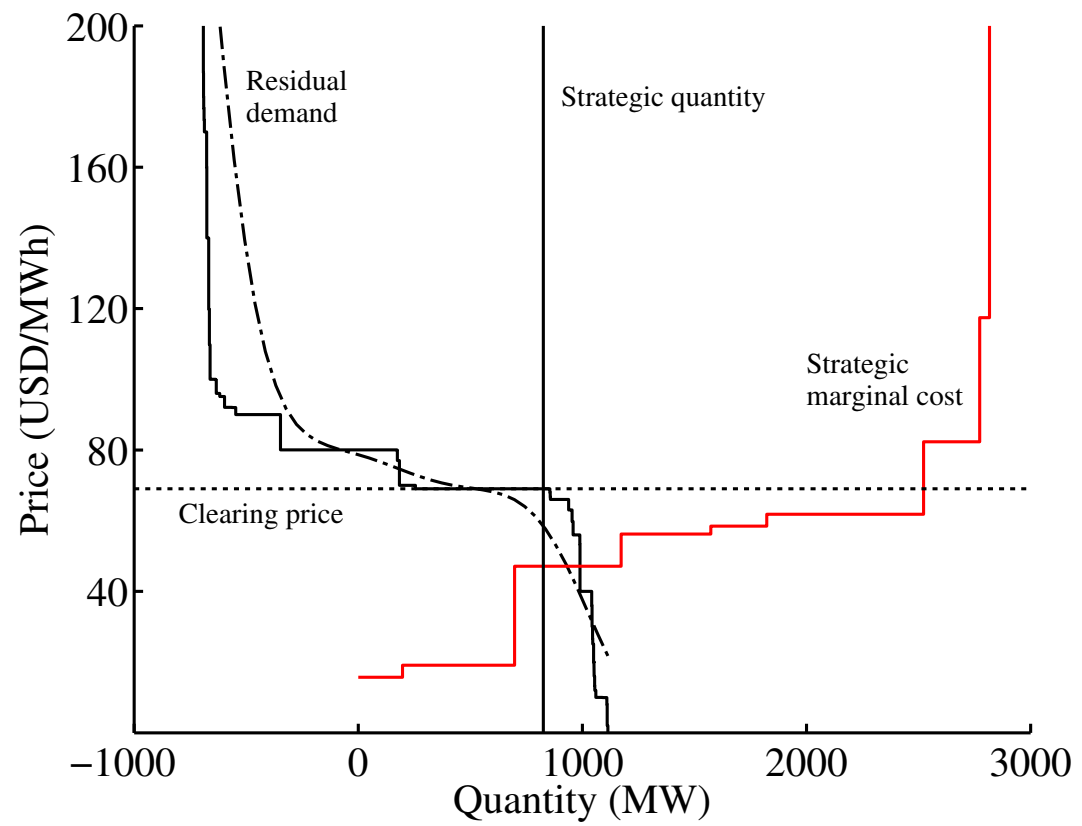

The figure shows the unconstrained market clearance on the Indian Energy Exchange during January 26th, 2010, hour 17. Panel A shows the actual market-clearing price as determined by the intersection of the downward-sloping demand curve and upward-sloping supply curve, where each curve has been shifted relative to the vertical axis by the volume of cleared buy and sell block bids, respectively. Panel B shows the determination of the simulated market-clearing price. The downward-sloping solid line is the residual demand curve consisting of demand and fringe supply bids and the dashed-and-dotted line a kernel-smoothed representation of this curve. The upward sloping solid line is the aggregate marginal cost curve of the strategic suppliers. The vertical line is the aggregate quantity offered by the strategic suppliers in equilibrium. The equilibrium is determined by the slope of the smoothed residual demand curve but the clearing price, which in this case is the same as the actual clearing price, is determined by the intersection of the strategic quantity with the true residual demand curve. 
Figure 3: Market Concentration by Transmission Constraint Status

A. Hypothetical unconstrained HHI, across hours B. Hypothetical unconstrained HHI, across hours when NR is in fact constrained

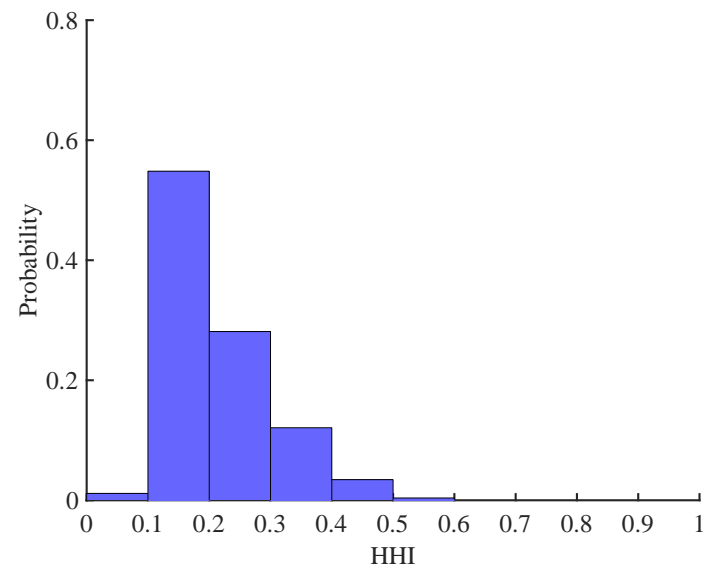

when SR is in fact constrained

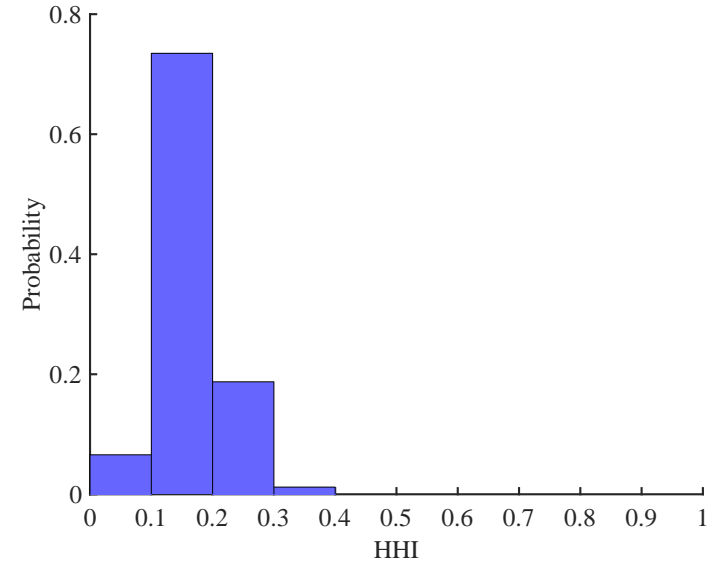

C. NR constrained HHI, across hours when NR is D. S1 constrained HHI, across hours when SR is in in fact constrained

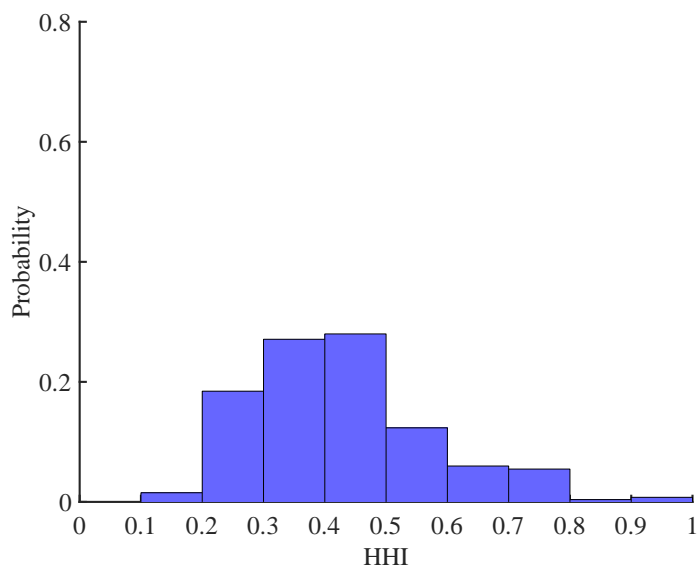

fact constrained

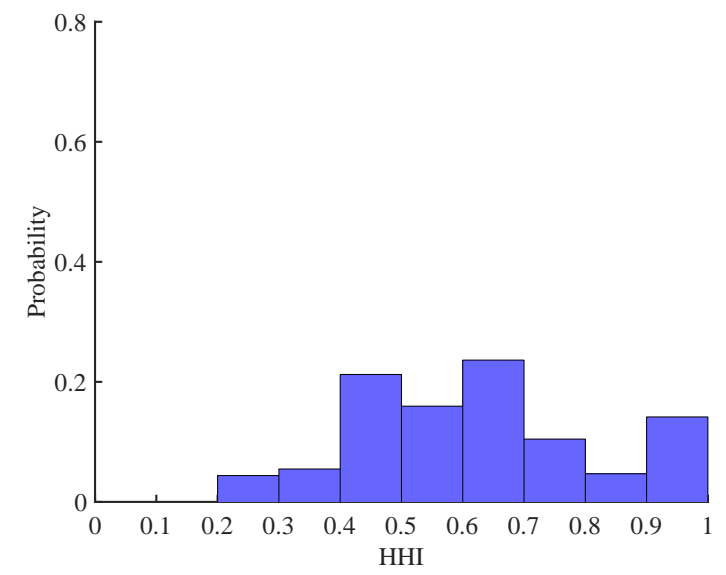

The figure shows the distribution of the Herfindahl-Hirschman Index (HHI) of market concentration when transmission constraints do not bind (top row) and bind (bottom row). The HHI is based on sellers' offered volumes. The sample is restricted to hours in which the North Region is constrained from the rest of the grid (Panels A and C), or in which the South Region is constrained from the rest of the grid (Panels B and D). The HHI is then computed, using the same offered volumes, either only in the constrained region (North in Panel A, South in Panel B), or within the grid as a whole (Panels C and D). The comparison is not between hours when the grid was constrained and hours when it was not, but between concentration in hours when the grid was constrained and concentration, in the same sample of hours and with the same bids, had the grid not been constrained (i.e., if more transmission capacity was built). 
Figure 4: Counterfactual Surplus with Relaxed Transmission Constraints
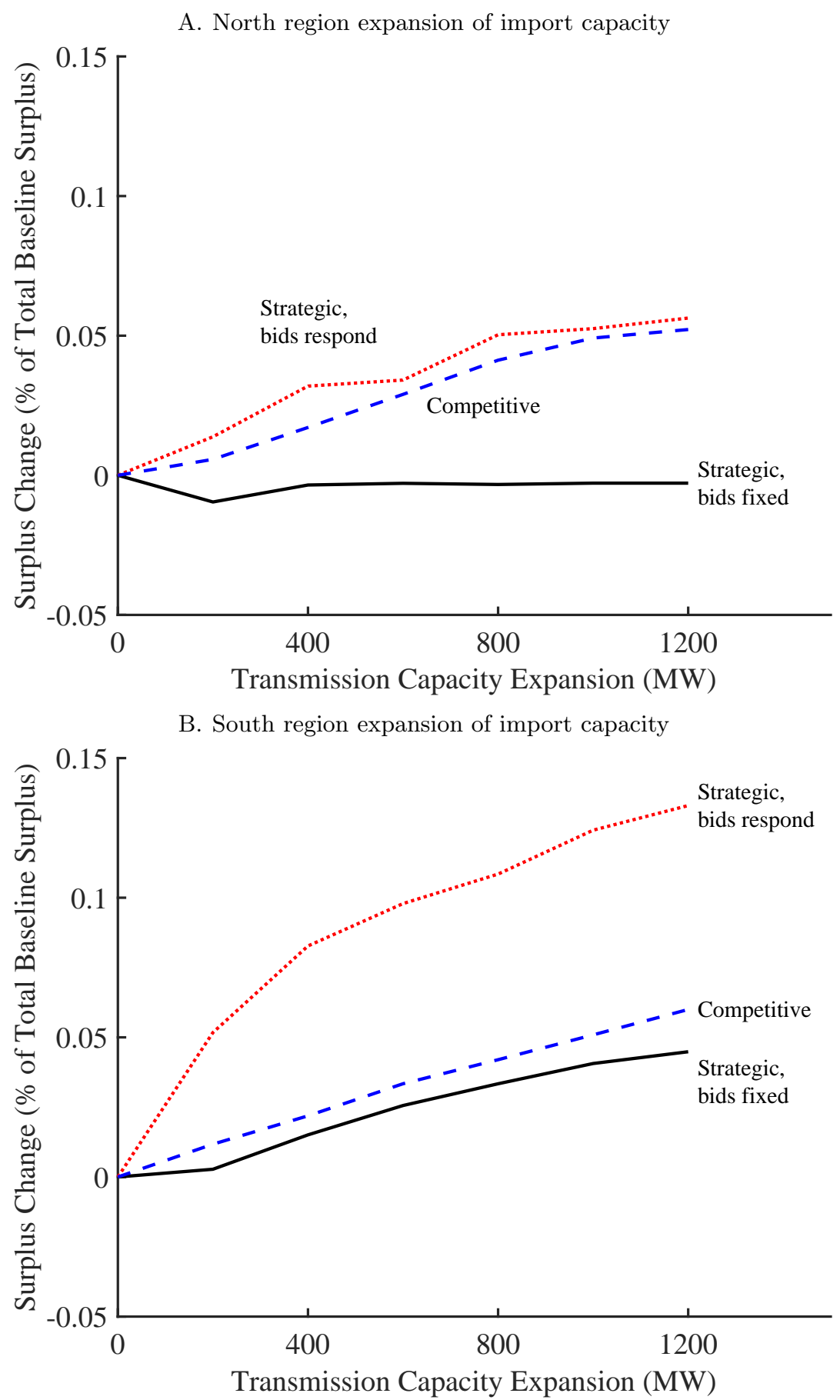

The figure shows changes in surplus for counterfactual increases of transmission capacity. Panel A shows expansions of capacity into the North region and Panel B into the South region. In each panel, the dashed line represents surplus in counterfactuals under competitive market conduct and the dotted line surplus under strategic Cournot conduct, where bids respond to the expansion of transmission. The solid line represents strategic Cournot conduct with bids held fixed at their baseline levels with no additional transmission capacity. Each surplus measure is scaled by subtracting the baseline surplus for each group and dividing by the total surplus. Each 0.05 share of total surplus represents an annual change of USD 27 million (INR 1.36 billion). 
Figure 5: Counterfactual Surplus by Region and Side of Market

A. North region expansion of import capacity (400 MW)

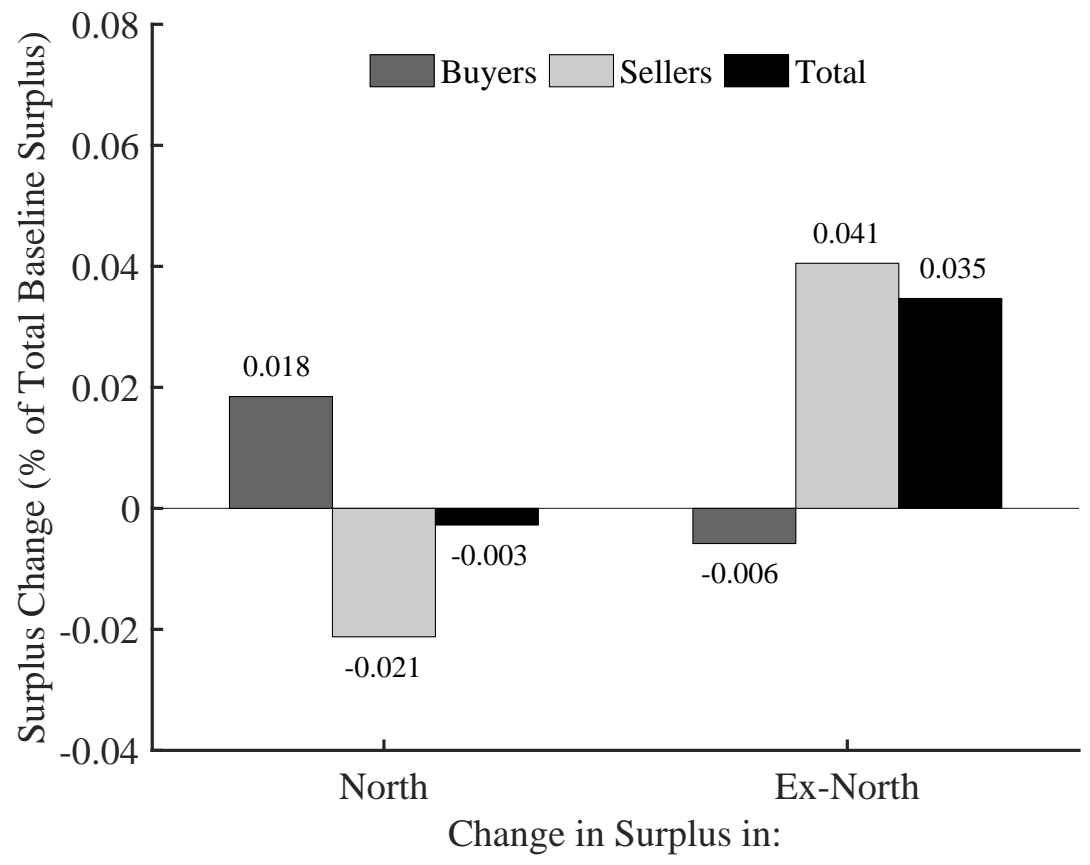

B. South region expansion of import capacity (400 MW)

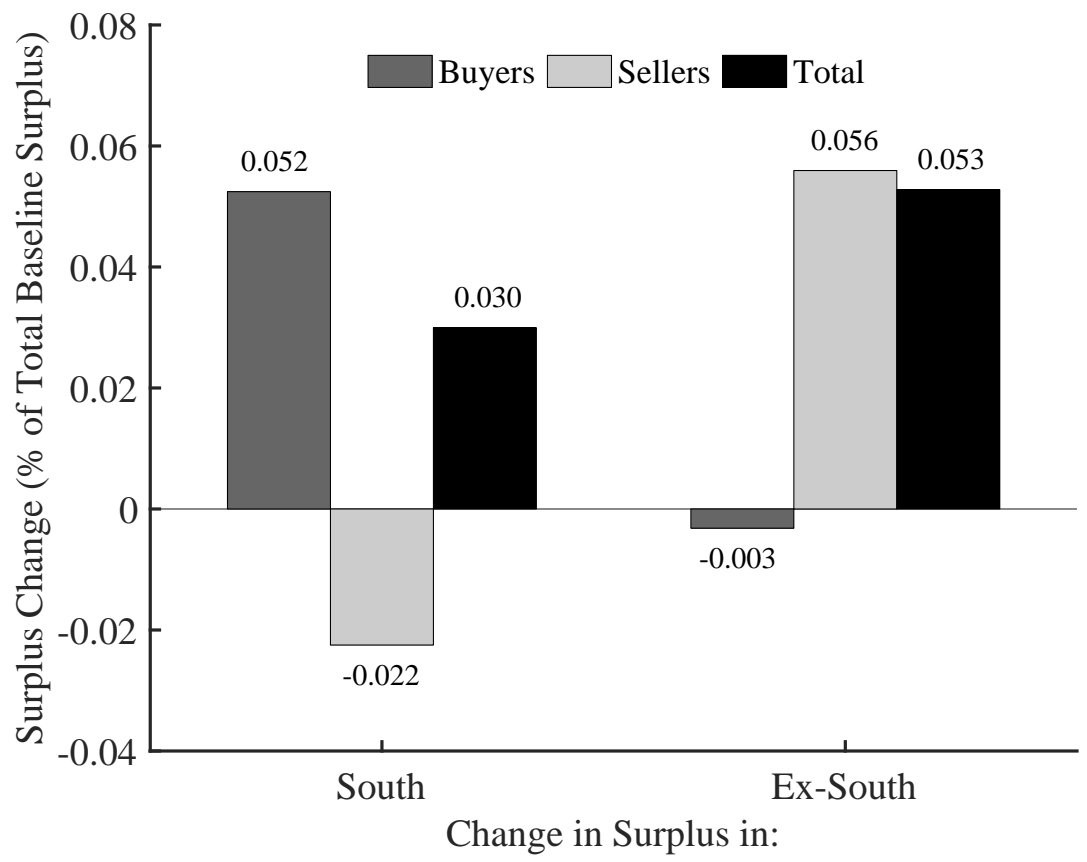

The figure shows the division of changes in surplus for counterfactual increases of transmission capacity across regions and sides of the market under strategic Cournot conduct, where bids respond to the expansion of transmission. Panel A shows expansions of $400 \mathrm{MW}$ capacity into the North region and Panel B into the South region. In each panel, the three bars grouped on the left represent changes in surplus for buyers (blue), sellers (red) and both sides together (black) in the importing region, while the three bars on the right represent changes for the exporting region. Each surplus measure is scaled by subtracting the baseline surplus for each group and dividing by the total surplus. Each 0.05 share of total surplus represents an annual change of USD 27 million (INR 1.36 billion). 


\section{Tables}

Table 1: Market and Bid Summary Statistics

\begin{tabular}{|c|c|c|c|c|c|c|}
\hline & $\begin{array}{c}\text { Mean } \\
\quad(1)\end{array}$ & $\begin{array}{c}\text { Std. Dev. } \\
(2)\end{array}$ & $\begin{array}{l}\text { Min. } \\
(3)\end{array}$ & $\begin{array}{c}\text { Median } \\
\quad(4)\end{array}$ & $\begin{array}{l}\text { Max. } \\
(5)\end{array}$ & $\begin{array}{l}\text { Obs. } \\
(6)\end{array}$ \\
\hline \multicolumn{7}{|c|}{ Panel A. Summary Over Hourly Auctions } \\
\hline Unconstrained price (USD/MWh) & 87.06 & 48.52 & 1.99 & 79.99 & 278.01 & 4344 \\
\hline Buy bids (number/auction) & 19.25 & 8.61 & 4.00 & 18.00 & 48.00 & 4344 \\
\hline Sell bids (number/auction) & 24.70 & 6.04 & 12.00 & 25.00 & 54.00 & 4344 \\
\hline \multicolumn{7}{|c|}{ Panel B. Summary Over Sell Bids } \\
\hline Sell bid ticks (number/bid) & 1.84 & 2.09 & 1.00 & 1.00 & 22.00 & 107304 \\
\hline Sell bid tick prices (USD/MWh) & 67.46 & 45.27 & 0.51 & 60.00 & 300.00 & 107304 \\
\hline Sell bid tick quantities (MW) & 33.73 & 67.47 & 0.25 & 9.10 & 1000.00 & 107304 \\
\hline
\end{tabular}

Summary statistics for bidding in the day-ahead market from November, 2009 through April, 2010. Panel A shows summary statistics for auction outcomes and participation, averaged over all hourly auctions in the sample period. Panel B shows summary statistics for sell bids over all sell bids offered in these auctions. Bids are step functions and tick quantities are incremental quantities for each step alone.

Table 2: Prevalence of Congestion

\begin{tabular}{|c|c|c|c|c|c|c|}
\hline & $\begin{array}{r}\text { Northeast } \\
\text { (1) }\end{array}$ & $\begin{array}{l}\text { East } \\
(2)\end{array}$ & $\begin{array}{l}\text { North } \\
(3)\end{array}$ & $\begin{array}{c}\text { South } 1 \\
(4)\end{array}$ & $\begin{array}{c}\text { South } 2 \\
(5)\end{array}$ & $\begin{array}{l}\text { West } \\
(6)\end{array}$ \\
\hline \multicolumn{7}{|c|}{ Panel A. Row Price Higher than Column (\%) } \\
\hline Northeast & & 0.2 & 0.2 & 0.1 & & 0.5 \\
\hline East & 0.4 & & & & & 0.3 \\
\hline North & 18.5 & 18.1 & & 17.8 & 17.4 & 18.2 \\
\hline South 1 & 23.5 & 23.1 & 23.0 & & & 23.3 \\
\hline South 2 & 26.7 & 26.3 & 26.2 & 7.1 & & 26.4 \\
\hline West & 0.4 & & & & & \\
\hline \multicolumn{7}{|c|}{ Panel B. Row Price less Column Price, Conditional on Being Higher } \\
\hline Northeast & & 14.9 & 7.7 & 5.6 & 2.0 & 12.4 \\
\hline East & 107.0 & & & & & 10.3 \\
\hline North & 35.4 & 33.8 & & 34.1 & 34.7 & 33.7 \\
\hline South 1 & 34.3 & 33.1 & 33.0 & & & 32.9 \\
\hline South 2 & 37.1 & 36.2 & 36.1 & 26.2 & & 36.1 \\
\hline West & 107.0 & & & & & \\
\hline
\end{tabular}

Summary statistics for congestion on the day-ahead market from November, 2009 through April, 2010. Panel A shows the percentage of hours during this period when the region labeling the row had a price greater than the price of the column region. Panel B shows the row region price less than column region price conditional on the row region price being greater. The mean unconstrained market-clearing price, a point of reference, is USD 87.06/MWh over the sample period. 
Table 3: Transmission Constraints and Market Competitiveness

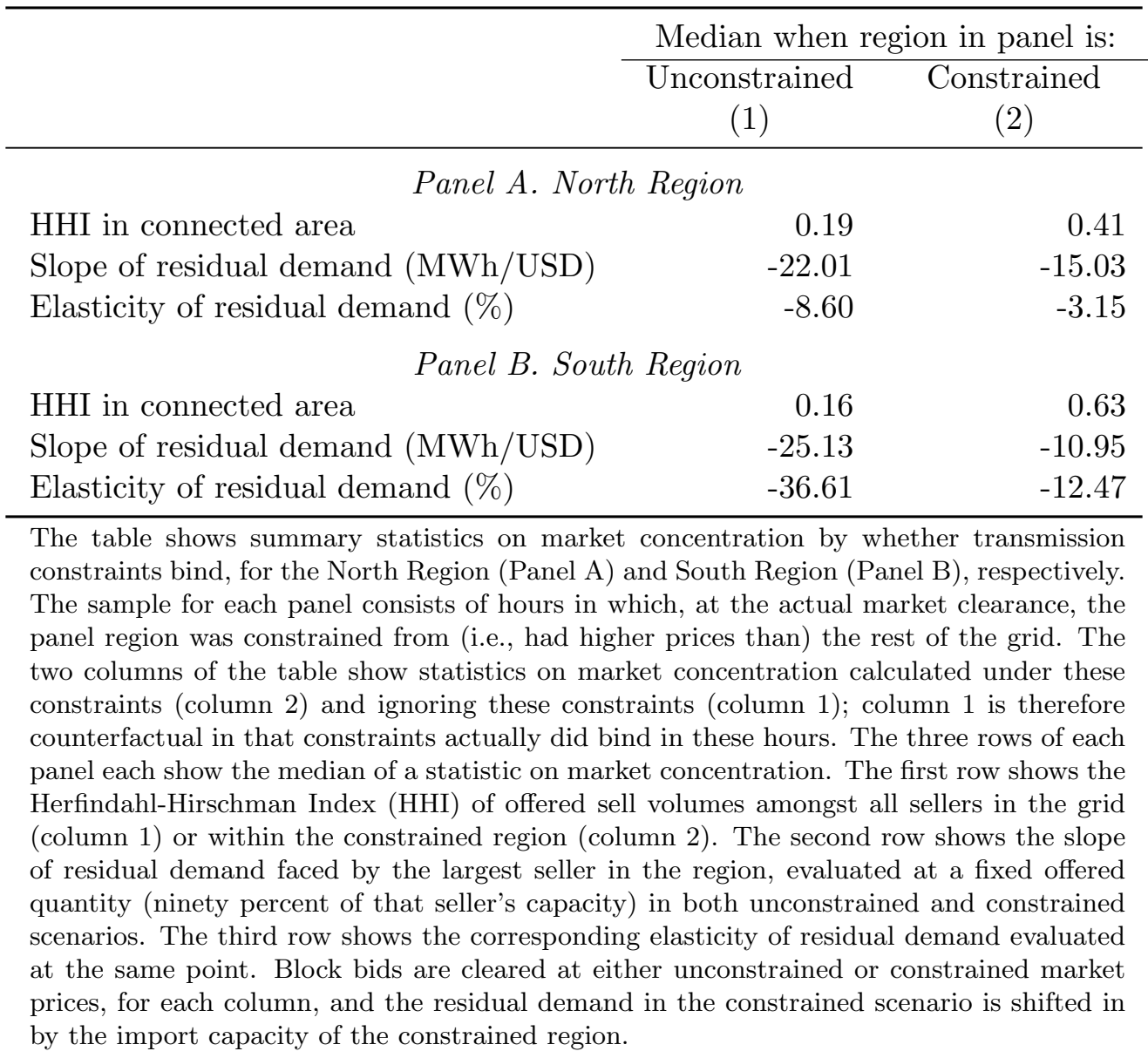


Table 4: Strategic Seller Characteristics and Estimated Marginal Costs

\begin{tabular}{|c|c|c|c|c|c|c|}
\hline $\begin{array}{l}\text { Region } \\
\text { (1) }\end{array}$ & $\begin{array}{l}\text { Type } \\
(2)\end{array}$ & $\begin{array}{r}\text { Share of } \\
\text { Vol. Off. } \\
(\%) \\
(3)\end{array}$ & $\begin{array}{r}\text { Maximum } \\
\text { Vol. Off. } \\
\text { (MW) } \\
(4)\end{array}$ & $\begin{array}{r}\text { Wtd. Mean } \\
\text { Tick Price } \\
\text { (USD/MWh) } \\
(5)\end{array}$ & $\begin{array}{r}\text { Estimated } \\
\text { Marginal Cost } \\
\text { (USD/MWh) } \\
(6)\end{array}$ & $\begin{array}{r}\text { Std. Err. } \\
\text { (USD/MWh) } \\
(7)\end{array}$ \\
\hline North & State Utility & 2.29 & 700 & 93.34 & 84.42 & $(6.93)$ \\
\hline North & Discom & 7.67 & 1000 & 60.41 & 57.47 & $(2.80)$ \\
\hline North & Discom & 6.56 & 500 & 73.39 & 68.91 & $(4.49)$ \\
\hline North & Discom & 1.07 & 475 & 87.54 & 100.01 & $(7.61)$ \\
\hline West & State Utility & 22.73 & 400 & 73.20 & 64.32 & $(1.55)$ \\
\hline West & State Utility & 10.90 & 250 & 48.46 & 39.98 & $(1.14)$ \\
\hline West & State Utility & 2.52 & 250 & 91.32 & 80.90 & $(2.02)$ \\
\hline West & Private Genco & 8.06 & 480 & 35.98 & 20.58 & $(1.32)$ \\
\hline West & Private Genco & 3.83 & 65 & 66.85 & 59.68 & $(1.01)$ \\
\hline West & Industrial Plant & 1.46 & 44 & 109.98 & 65.64 & $(3.43)$ \\
\hline West & Industrial Plant & 1.36 & 36 & 132.39 & 121.05 & $(3.94)$ \\
\hline West & Industrial Plant & 1.22 & 250 & 36.57 & 45.06 & $(0.76)$ \\
\hline West & Industrial Plant & 1.03 & 198 & 14.90 & 14.32 & $(2.12)$ \\
\hline
\end{tabular}

Statistics for bidding by strategic sellers on the day-ahead market from November, 2009 through April, 2010 and estimated marginal costs. Region is the region in which the seller bids, type is the category of bidder to which the seller belongs, share of total volume offered is the share of offered volume offered by each seller, weighted mean tick price is the quantity-weighted average price of bid ticks offered by the seller, estimated marginal costs are the costs recovered via the estimation described in Section 5, using lagged temperature to instrument for the estimation moments. Standard errors are bootstrapped by resampling 100 bootstrap iterations with replacement over both days in the sample and simulated market outcomes. Strategic sellers are those sellers in the North and West region with at least one percent market share as determined by the share of offered volume. 
Table 5: Model Fit

\begin{tabular}{|c|c|c|c|c|}
\hline & \multicolumn{2}{|c|}{ Actual } & \multicolumn{2}{|c|}{ Model } \\
\hline & $\begin{array}{r}\text { Mean } \\
(1)\end{array}$ & $\begin{array}{c}\text { Std Dev } \\
(2)\end{array}$ & $\begin{array}{c}\text { Mean } \\
(3)\end{array}$ & $\begin{array}{c}\text { Std Dev } \\
(4)\end{array}$ \\
\hline \multicolumn{5}{|c|}{ Panel A. Unconstrained } \\
\hline Clearing price (USD/MWh) & 87.06 & 48.52 & 75.52 & 34.20 \\
\hline Clearing quantity (MW) & 936.82 & 328.64 & 1225.49 & 505.98 \\
\hline \multicolumn{5}{|c|}{ Panel B. Constrained, North region } \\
\hline Clearing price (USD/MWh) & 86.85 & 48.52 & 77.80 & 35.30 \\
\hline Price $>$ West price $(\%$ of hrs $)$ & 0.18 & 0.39 & 0.17 & 0.37 \\
\hline Price - West Price (if not equal) & 33.71 & 21.84 & 28.18 & 19.24 \\
\hline Net demand (MW) & 258.45 & 244.49 & 348.25 & 261.10 \\
\hline \multicolumn{5}{|c|}{ Panel C. Constrained, South 1 region } \\
\hline Clearing price (USD/MWh) & 88.39 & 51.20 & 85.60 & 45.05 \\
\hline Price $>$ West price $(\%$ of hrs $)$ & 0.23 & 0.42 & 0.32 & 0.47 \\
\hline Price - West Price (if not equal) & 32.94 & 24.58 & 39.54 & 25.18 \\
\hline Net demand (MW) & -81.10 & 180.84 & -81.55 & 186.13 \\
\hline \multicolumn{5}{|c|}{ Panel D. Constrained, West region } \\
\hline Price (USD/MWh) & 80.72 & 48.06 & 75.20 & 37.12 \\
\hline Net demand (MW) & -346.12 & 247.01 & -459.53 & 299.67 \\
\hline
\end{tabular}

The table shows the fit of the Cournot model to market outcomes on the day-ahead market from November, 2009 through April, 2010. In each panel the first two columns show the mean and standard deviation of each outcome for the actual market clearance, using the bids submitted to the exchange. Columns 3 and 4 show market outcomes under the Cournot model equilibrium. The Panels represent different treatments of transmission constraints. In Panel A the clearance is conducted and the model is solved assuming no transmission constraints exist. Note that the unconstrained clearance benchmark of Panel A, columns 1 and 2, commonly used by the exchange, is itself a naïve counterfactual, conducted using bids submitted under constrained conditions. In Panels B through D, market outcomes from constrained clearance are shown using bids as submitted and as predicted by the model. 
Table 6: Counterfactual Market Outcomes with Expanded Transmission Capacity

\begin{tabular}{|c|c|c|c|c|c|}
\hline \multirow{4}{*}{$\begin{array}{l}\text { Market conduct } \\
\text { Do bids respond? } \\
\text { Transmission expansion? }\end{array}$} & \multicolumn{2}{|c|}{ Competitive } & \multicolumn{3}{|c|}{ Strategic } \\
\hline & Base & Fixed & Base & Fixed & Respond \\
\hline & No & Yes & No & Yes & Yes \\
\hline & (1) & $(2)$ & $(3)$ & (4) & $(5)$ \\
\hline \multicolumn{6}{|c|}{ Panel A. North region $400 M W$ expansion } \\
\hline \multicolumn{6}{|l|}{ Regional Prices } \\
\hline North $>$ West $(\%$ of hrs $)$ & 0.18 & 0.11 & 0.17 & 0.02 & 0.08 \\
\hline North - West (USD/MWh) & 36.39 & 31.22 & 28.18 & 21.22 & 24.97 \\
\hline \multicolumn{6}{|l|}{ Regional Net Demand (MW) } \\
\hline North & 261.32 & 320.29 & 348.25 & 347.99 & 412.38 \\
\hline South 1 & -84.44 & -89.98 & -81.55 & -84.06 & -84.62 \\
\hline West & -337.86 & -370.83 & -459.53 & -443.60 & -510.55 \\
\hline \multicolumn{6}{|l|}{ Surplus (USD'000s) } \\
\hline Market & 37.16 & 38.23 & 61.94 & 61.73 & 63.92 \\
\hline Buyer's & 13.87 & 14.03 & 21.33 & 25.29 & 22.12 \\
\hline Seller's & 23.29 & 24.19 & 40.61 & 36.44 & 41.81 \\
\hline \multicolumn{6}{|c|}{ Panel B. South region $400 M W$ expansion } \\
\hline \multicolumn{6}{|l|}{ Regional Prices } \\
\hline South $1>$ West (\% of hrs) & 0.29 & 0.09 & 0.32 & 0.08 & 0.09 \\
\hline South 1 - West (USD/MWh) & 30.40 & 29.12 & 39.54 & 30.20 & 30.42 \\
\hline \multicolumn{6}{|l|}{ Regional Net Demand (MW) } \\
\hline North & 261.32 & 225.76 & 348.25 & 270.15 & 305.34 \\
\hline South 1 & -84.44 & -48.76 & -81.55 & -40.64 & -28.29 \\
\hline West & -337.86 & -362.20 & -459.53 & -448.97 & -508.53 \\
\hline \multicolumn{6}{|l|}{ Surplus (USD'000s) } \\
\hline Market & 37.16 & 38.52 & 61.94 & 62.88 & 67.07 \\
\hline Buyer's & 13.87 & 14.45 & 21.33 & 22.79 & 24.38 \\
\hline Seller's & 23.29 & 24.07 & 40.61 & 40.09 & 42.68 \\
\hline \multicolumn{6}{|c|}{ Panel C. South region $1200 \mathrm{MW}$ expansion } \\
\hline \multicolumn{6}{|l|}{ Regional Prices } \\
\hline South $1>$ West (\% of hrs) & 0.29 & 0.00 & 0.32 & 0.00 & 0.00 \\
\hline South 1 - West (USD/MWh) & 30.40 & 16.23 & 39.54 & 34.70 & 20.59 \\
\hline \multicolumn{6}{|l|}{ Regional Net Demand (MW) } \\
\hline North & 261.32 & 209.86 & 348.25 & 250.23 & 277.04 \\
\hline South 1 & -84.44 & -22.57 & -81.55 & -18.58 & 17.97 \\
\hline West & -337.86 & -372.76 & -459.53 & -451.10 & -527.30 \\
\hline \multicolumn{6}{|l|}{ Surplus (USD'000s) } \\
\hline Market & 37.16 & 40.88 & 61.94 & 64.72 & 70.18 \\
\hline Buyer's & 13.87 & 15.46 & 21.33 & 23.46 & 26.48 \\
\hline Seller's & 23.29 & 25.42 & 40.61 & 41.26 & 43.71 \\
\hline
\end{tabular}

The table shows counterfactual market outcomes under different assumptions on transmission capacity, across panels, and market conduct, across columns. Column 1 represents competitive market clearance with no transmission expansion. Column 2 represents competitive conduct with transmission expansions as shown in each panel. Column 3 represents Cournot market clearance with no transmission expansion. Column 4 is Cournot conduct with fixed bids, where the quantities offered by strategic sellers in equilibrium are found at the baseline level of transmission, then held fixed as transmission expands. Column 5 represents Cournot conduct with endogenous bids that respond to transmission expansions as shown in each panel. Within each panel, market prices, quantities and surplus are shown, for the regions or parties indicated in the row headings. 
Table 7: Estimated Cost of Transmission Capacity Expansions into North and South Regions

\begin{tabular}{|c|c|c|c|}
\hline & $\begin{array}{r}\text { Annual } \\
\text { Cost/Benefit } \\
\text { (USD millions) }\end{array}$ & Planned Grid Element & Source of Cost Estimate \\
\hline \multicolumn{4}{|c|}{ Panel A. North region capacity expansion of $400 \mathrm{MW}$} \\
\hline Amortized cost & $\begin{array}{r}1.70 \\
3.50 \\
5.40 \\
10.60\end{array}$ & $\begin{array}{l}2 \text { X } 500 \text { MVA Substation } \\
2 \text { X } 200 \text { kVA Line-in Line-out } \\
450 \text { km } 400 \text { kV Line Rajarhat-Purnea }\end{array}$ & $\begin{array}{l}\text { Pet. No. 89/2012, Jaipur South } \\
\text { Pet. No. 89/2012, Jaipur South } \\
\text { Pet. No. 96/2008, RAPP-Kankroli }\end{array}$ \\
\hline Annual surplus & 17.52 & & \\
\hline Ratio of surplus/cost & 1.65 & & \\
\hline Amortized cost & $\begin{array}{r}P \\
11.28 \\
2.58 \\
13.86\end{array}$ & $\begin{array}{l}\text { nel B. South region capacity expansion of } 400 \mathrm{MW} \\
1600 \mathrm{~km} \text { HVDC Line and Stations Talcher-Kolar } \\
400 \mathrm{kV} \text { DC Talcher-Rourkela }\end{array}$ & $\begin{array}{l}\text { Pet. No. } 84 / 2005 \text {, Talcher-Kolar } \\
\text { Pet. No. 146/2010, Talcher-Rourkela }\end{array}$ \\
\hline Annual surplus & 44.94 & & \\
\hline Ratio of surplus/cost & 3.24 & & \\
\hline $\begin{array}{l}\text { The table presents a cost-l } \\
\text { Region. The grid element } \\
\text { of India Limited (2009). } \\
\text { while the grid elements to } \\
\text { each grid element are from } \\
\text { (CERC), available at www } \\
\text { maintenance costs but not } \\
\text { is computed at the higher } \\
\text { market surplus each year i }\end{array}$ & $\begin{array}{l}\text { nefit analysis of new } \\
\text { to be constructed in } \\
\text { he grid elements to } \\
\text { lieve congestion int } \\
\text { ranted petitions for } \\
\text { ercind.gov.in/orders } \\
\text { turn on equity. The } \\
\text { te given in Pet. No. } \\
\text { the day-ahead mark }\end{array}$ & $\begin{array}{l}\text { ransmission investment to relieve congestion from the East to } \\
\text { order to relieve congestion are from National Load Dispatch } \\
\text { lieve congestion into the North Region are part of an exp } \\
\text { he South Region are inferred from the planning and transmi } \\
\text { ost reimbursement for comparable grid elements filed with th } \\
\text { tml. Cost estimates are on an annual, amortized basis and in } \\
\text { ength of the Talcher II-Rourkela link is from the petition cite } \\
/ 2008 \text {. All costs are scaled to represent a } 400 \mathrm{MW} \text { capacity }\end{array}$ & $\begin{array}{l}\text { the North Region and the East to the South } \\
\text { Centre (2012) and Power Grid Corporation } \\
\text { cit plan from the system operator (NLDC) } \\
\text { sion capacity documents. Cost estimates for } \\
\text { Central Electricity Regulatory Commission } \\
\text { lude depreciation, interest and operations \& } \\
\text { in the table but the cost of building the line } \\
\text { cpansion. Annual surplus is the total gain in } \\
\text { ulated by assuming the gain in surplus over }\end{array}$ \\
\hline
\end{tabular}




\section{A Appendix: Institutions (Not for Publication)}

\section{(a) Real-time Balancing through Unscheduled Interchange}

The prices for real-time balancing, called unscheduled interchange in the Indian market, depend on the grid frequency, which in turn depends on the balance between demand and supply on the grid. When demand exceeds supply, as is often the case, the grid frequency drops below its nominal frequency of $50 \mathrm{~Hz}$ and sellers (buyers) are paid for injecting more (drawing less) power than scheduled. This mechanism takes the place that real-time balancing markets with advance bidding serve in other power systems.

The balancing or UI price is a piecewise linear function of grid frequency. As part of a general effort to prevent buyers and sellers from relying on UI and to improve the balance of demand and supply, which affects grid stability, the relationship between the UI price and the grid frequency has become steeper over time. On April 1st, 2009 the price schedule was increased so that the UI price increased by USD 3.1/MWh (INR 155/MWh) for each 0.02 $\mathrm{Hz}$ change in grid frequency and on May 1st, 2010 increased again to USD 4.3/MWh (INR 215/MWh) for each $0.02 \mathrm{~Hz}$ change. The net effect of these changes has been to discourage over-demand through UI and push buyers and sellers back into the scheduled markets.

There are also regulatory limitations on the use of UI designed to prevent withholding from the scheduled power markets. The UI charges paid to sellers are capped and the maximum allowable deviation from schedule also capped (Central Electricity Regulatory Commission, 2009) The UI regulation also explicitly threatens sellers that persistently deviate from schedule with regulatory action.

\section{(b) Arbitrage between short-term market segments}

Appendix Table A1 shows the correlations between prices across the different short-term

market segments at hourly (Panel A) and weekly (Panel B) frequencies. The sample period is 2009 and 2010. The prices are as follows. For the day-ahead market, the unconstrained hourly clearing prices on the Indian Energy Exchange and the Power Exchange India, the two exchanges that make up all trade. For the balancing market, the unscheduled interchange price, calculated by applying the UI Regulations' administered price schedule to the grid frequency. We take the average of the UI price for the Northern-Eastern-Western (NEW) 
grid and the Southern grid. For contracts, we take the volume-weighted average price of all single-day short-term contracts (signed between 365 and one day in advance of delivery), across all regions of the grid. The timing of the prices is lined up across markets based on the date of delivery of electricity; therefore, because contracts are signed at various times in advance, the contracts may have been agreed up to one year prior to delivery (though most are agreed within a month before delivery).

Table A1: Price Correlations Across Short-term Market Segments

\begin{tabular}{|c|c|c|c|c|}
\hline & $\begin{array}{l}\text { IEX } \\
(1)\end{array}$ & $\begin{array}{l}\text { PXI } \\
(2)\end{array}$ & $\begin{array}{c}\text { Balancing } \\
(3)\end{array}$ & $\begin{array}{c}\text { Contracts } \\
(4)\end{array}$ \\
\hline \multicolumn{5}{|c|}{ Panel A. Hourly Frequency } \\
\hline Day-ahead price, IEX, unconstrained & 1 & & & \\
\hline Day-ahead price, PXI, unconstrained & $0.915^{* * *}$ & 1 & & \\
\hline Balancing price (unscheduled interchange) & $0.598^{* * *}$ & $0.602^{* * *}$ & 1 & \\
\hline \multicolumn{5}{|c|}{ Panel B. Weekly Frequency } \\
\hline Day-ahead price, IEX, unconstrained & 1 & & & \\
\hline Day-ahead price, PXI, unconstrained & $0.978^{* * *}$ & 1 & & \\
\hline Balancing price (unscheduled interchange) & $0.808^{* * *}$ & $0.824^{* * *}$ & 1 & \\
\hline Short-term contract weighted average price & $0.714^{* * *}$ & $0.774^{* * *}$ & $0.664^{* * *}$ & 1 \\
\hline \multicolumn{5}{|c|}{$\begin{array}{l}\text { The table shows correlations between market prices on various short-term Indian power markets at } \\
\text { hourly (Panel A) and weekly (Panel B) frequencies. The prices are as follows. For the day-ahead } \\
\text { market, the unconstrained hourly clearing prices on the Indian Energy Exchange and the Power } \\
\text { Exchange India, the two exchanges that make up all trade. For the balancing market, the unscheduled } \\
\text { interchange price, calculated by applying the UI Regulations' administered price schedule to the grid } \\
\text { frequency. The balancing or UI price is a piecewise linear function of grid frequency. We take the } \\
\text { average of the UI price for the North, East and Western grids (NEW) and the Southern grid. For } \\
\text { contracts, we take the volume-weighted average price of all single-day short-term contracts (signed } \\
\text { between } 365 \text { and one day in advance of delivery), across all regions of the grid. The sample period is } \\
2009 \text { and } 2010 \text {. The symbol }{ }^{*} \text { denotes } p<0.05,{ }^{* *} p<0.01 \text { and }{ }^{* * *} p<0.001 \text { for a test of the null } \\
\text { that the correlation between the row and column price series is zero. }\end{array}$} \\
\hline
\end{tabular}

\section{(c) Transmission allocation}

The transmission capacity limits determined by the NLDC are allocated among the different segments of the power market in an administrative manner. Long-term customers, which are charged for building and maintaining the transmission grid in proportion to their generation capacity, are given first priority (Central Electricity Regulatory Commission, 2008b). The allocation of capacity to long-term trade is nearly constant over time. The margin left after long-term use, due to design margins, short-term variation in power flows and spare transmission capacity due to anticipated future load, is left to short-term trade including both contracts and the day-ahead market (Central Electricity Regulatory Commission, 2008a). 
Short-term contractual buyers may book up the corridor that has been reserved for shortterm trade on a first-come, first-served basis before the power exchanges. This reservation of the corridor continues until three days prior to the day of delivery, at which time bookings are frozen and the remaining transmission capacity reserved for use by power exchanges. On average, of the corridor that is available for short-term use, more than half is left over for use by the power exchanges. However, in some hours short-term contracts use up all the corridor

for short-term trade, in which case power exchanges must solve for market clearance with zero flows between the regions where corridor has been exhausted.

\section{(d) Inter-regional power flows and price differences}

The above transmission allocation process means that, although the amount of physical transmission line does not vary, the amount available for use by the day-ahead market does vary. This variation in available capacity is not exogenous to market conditions, since it depends on how much corridor has been booked up by contract market participants. We may still be interested to see, on this intensive margin, how the severity of transmission constraints is correlated with regional price differences. 
Figure A1: Regional Price Differences Against Interregional Flows

A. East to North

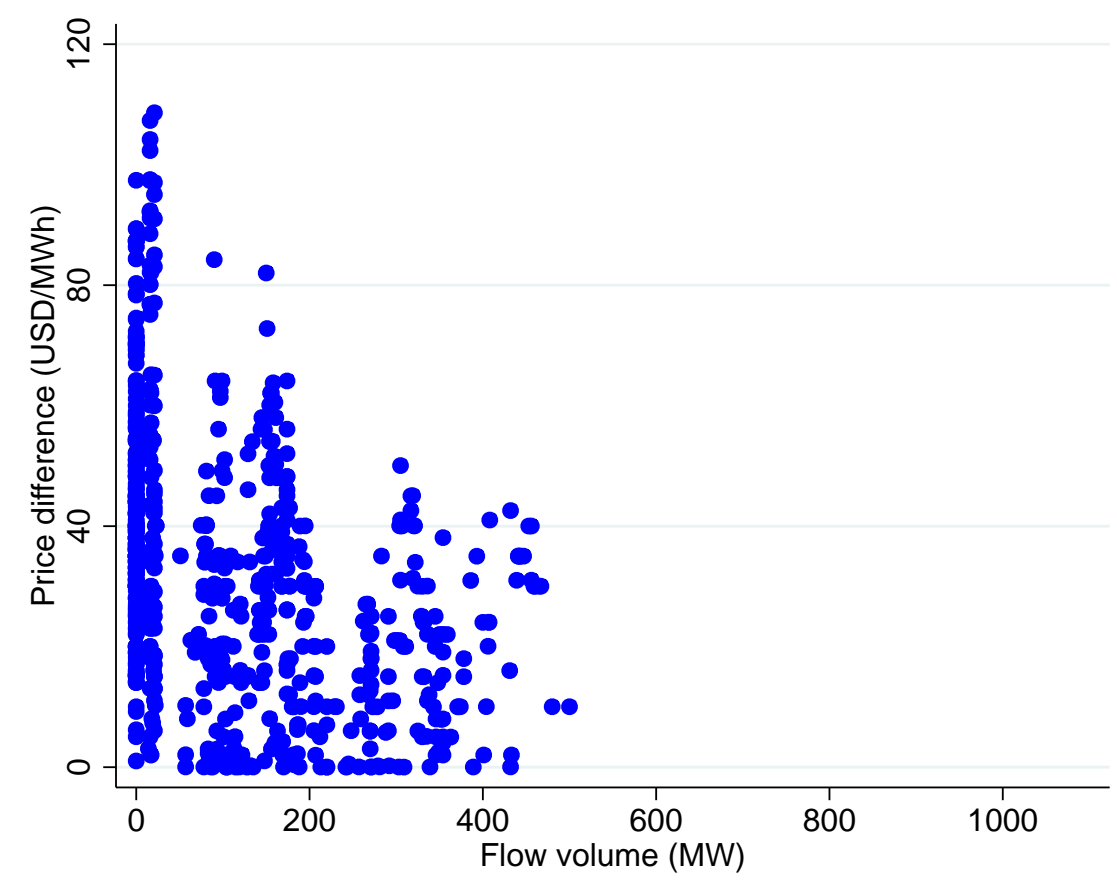

B. East to South

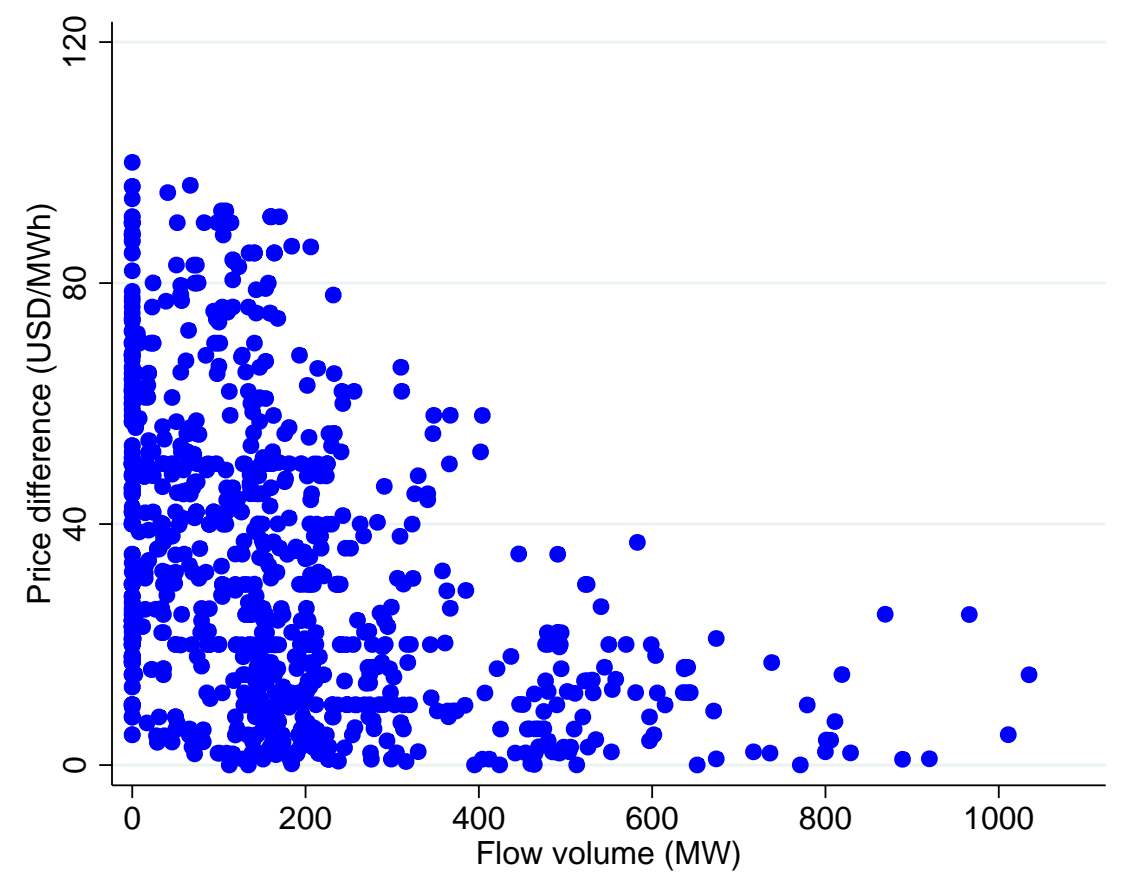

The figure plots the price difference between two regions against the power flow between two regions for the East to North and East to South corridors respectively, conditional on a transmission constraint between each pair of regions binding, during the sample period of November, 2009 through April, 2010. The price difference is the South or North price less the East price and the flow the net supply from the East region. A constraint binding implies that the price difference is weakly positive. 
Figure A1 charts regional price differences against inter-regional power flows for the East and North regions (Panel A) and the East and South 1 regions (Panel B). The horizontal axis shows the flow between regions, with positive flow indicating the net supply from the East region, and the vertical axis shows the difference between the North or South 1 price and the East price. The panels show only hours when the flow between regions is constrained, causing the constrained areas including each region to be cleared separately and the market-clearing prices in the two regions to differ. ${ }^{37}$ As shown in Panel A, power flow being constrained at low levels, below $200 \mathrm{MW}$, is associated with price differences of USD 100/MWh or above in both regions. These price differences across regions are larger than the average unconstrained clearing price. When more transmission capacity is available, the greater flow between regions eliminates or reduces the price difference, creating the strong negative correlation between price differences and constrained flow in the figure. A similar pattern of price differences decreasing in constrained flow is seen between the South 1 region and the East (Panel B), though a greater flow is needed to close the price gap for this pair.

\section{B Appendix: Market-clearing and Estimation (Not for Pub- lication)}

\section{(a) Discretization of Single Bids}

The Indian Energy Exchange allows bids to be piecewise-linear functions from price to quantity defined by up to 64 price-quantity pairs. Most bidders use only a small fraction of the available ticks and, moreover, submit bid functions that approximate step correspondences. For example, using the original currency in which bids are submitted, a seller will submit a bid that is equal to zero up to INR 2499/MWh, that discretely steps up over the minimum allowable INR 1/MWh bidding increment to $50 \mathrm{MW}$ at INR 2500/MWh, and remains constant thereafter.

Table B2 summarizes this behavior for sell bids during the study period of November, 2009 through April, 2010. The percentage of bid segments with any slope is 4.18 for fringe

\footnotetext{
${ }^{37}$ Note that the constraints bind at different levels of flow. The available physical capacity of lines varies a small amount from hour to hour, but there is greater variation in the capacity declared for the day-ahead market due to the booking of corridor for the clearance of prior markets. If a line can support $3500 \mathrm{MW}$ and $3000 \mathrm{MW}$ is booked prior to the day-ahead market, then transmission capacity for the day-ahead market is the residual $500 \mathrm{MW}$.
} 
bids and 1.54 for strategic bids. Sloping bid segments do supply a greater quantity than flat segments, at 5.14 and 15.73 percent, respectively, but the share of total quantity offered is still low. Because of the limited use of sloping bid segments, single bids are best represented as discrete step functions. For those bids that do have slope, I approximate sloping segments with discrete steps spaced equally within the price range of the bid segment, at up to USD 5/MWh intervals, such that the average quantity supplied over the segment is the same as in the original bid.

Table B2: Prevalence of Sloping Bid Segments in Sell Bids

\begin{tabular}{lrr}
\hline & Fringe & Strategic \\
\hline Bid segment has slope & 4.18 & 1.54 \\
Percentage of quantity with slope & 5.14 & 15.73 \\
\hline
\end{tabular}

The limited use of bid slope observed may be because the losses to discrete bidding are small and/or the fixed costs of optimal bidding are large (Kastl, 2012; Hortaçsu and Puller, 2008).

\section{(b) Treatment of Block Bids}

Single bids are hourly functions from price to quantity that are submitted and cleared indepedently for each hour. Block bids specify the maximum willingness-to-pay of a buyer or minimum willingness-to-accept of a seller on average over a continuous block of hours. Each block is specified by a price and quantity $p^{b}, q^{b}$ and a set of hours $H^{b}$. Blocks allow bidders to reflect cost complementarities in supplying power in contiguous hours, similarly to complex bids (Reguant, 2014). Unlike complex bids, which impose a minimum revenue requirement on the revenues earned by single bids, block bids do not constrain or change the clearance of single bids, other than through their effect on the market-clearing price.

A bidder offering both single and block bids would consider the effect of single bid tick prices on block bid clearance and costs. Let $\hat{p}=\sum_{h \in H^{b}} p_{h} /\left|H^{b}\right|$ be the average hourly price over a block and $G\left(\cdot \mid H^{b}\right)$ be the cumulative distribution function of this price and let $\delta^{b}$ indicate the event that the block is cleared. In terms of equation 1, the bidder's first-order 
condition for a single bid tick when also bidding with blocks becomes:

$$
\begin{aligned}
& \mathbb{E}_{\sigma_{-i t}}\left[\frac { \partial p } { \partial b _ { i t k } } \left(q_{i t}(p)+\frac{\partial D_{i t}^{r}}{\partial p} p+\right.\right. \\
& \frac{\partial D_{i t}^{r}}{\partial p}\left(\delta^{b} C^{\prime}\left(q_{i t}(p)+q^{b}\right)+\left(1-\delta^{b}\right) C^{\prime}\left(q_{i t}(p)\right)\right)+ \\
& \left.\left.\frac{1}{\left|H^{b}\right|}\left(q^{b}+G_{\hat{p}}\left(p^{b} \mid H^{b}\right)\left[C\left(q_{i t}(p)+q^{b}\right)-C\left(q_{i t}(p)\right)\right]\right)\right)\right]\left.\right|_{p=b_{i t k}}=0
\end{aligned}
$$

The first two revenue terms are the same as in the original condition. The second line is a weighted average of marginal costs over whether a block is included or not, as block clearance shifts a firm along its cost curve. The third line is the change in revenue for the block due to the bid tick changing the average price at which the block is cleared and the non-marginal change in costs from the block being included or not. ${ }^{38}$

Block bids, considered through this modified first-order condition, are not empirically important to the single bids of strategic firms. In the above first-order condition, blocks will matter if block inclusion has a large effect on marginal costs, if the single bid price is likely to change the distribution of average prices faced by the block and if the block volume is large. None of these conditions hold empirically. Given that marginal costs are assumed constant in the estimation, block inclusion does not shift marginal costs and the second line of this condition reduces to the product of residual demand slope and constant marginal cost. The average block bid submitted by a strategic bidder applies to a block of $\left|H^{b}\right|=11$ hours, which via line three makes it unlikely that a single bid tick from a single hour will have a noticeable effect on the distribution of block prices. Strategic bidders, moreover, offer only 9.1 percent of their total offered volume through blocks, summing block volume over all the hours to which a block applies, meaning that the effect of block prices on revenue is then also small as $q^{b}<<q_{i t}(p)$. For these reasons I assume in the estimation that strategic bidders do not account for the presence of block bids.

Block bids are still a feature of the market environment and so I replicate the block clearing of the exchange in order to match market outcomes. Auctions with blocks are combinatorial, with the clearance of each block depending on the clearance of the others via market prices, so there is not necessarily a unique set of cleared blocks or cleared market-clearing prices over the day (Meeus, Verhaegen and Belmans, 2009). The set of blocks cleared will rather

\footnotetext{
${ }^{38} \mathrm{I}$ neglect any feedback of the block clearance onto single bids during other hours of the day.
} 
depend on the algorithm for block clearance. The precise algorithm of the exchange is not publicly available. I use a heuristic algorithm that iteratively drops blocks until a set of hourly market-clearing prices is found:

1. Assume all block bids are cleared.

2. Clear the market for each constrained area in all 24 hours of the day.

3. Calculate the difference between the block price $p^{b}$ and the average hourly price $\hat{p}$ in the hours to which a block applies, $\Delta p=(1-2 \cdot \mathbf{1}\{$ BuyBlock $\})\left(p^{b}-\hat{p}\right)$.

- If $\Delta p>0$ for any cleared block, designate block with the largest $\Delta p$ as not cleared and return to (1).

- Otherwise exit.

I do not generally attempt to reinclude blocks that have been dropped at an earlier stage of clearance but may be cleared at the market-clearing prices of later iterations. In step (3) if any block is on the excess side of the market during an hour with an extremal (floor or ceiling) price, that block is given preference to be dropped regardless of whether it has the largest $\Delta p$ overall. Similarly if at exit the price is extremal in any hour and any blocks on the anti-excess side of the market were not cleared I reinclude such blocks until they are exhausted or the price is no longer extremal.

\section{(c) Market-splitting Algorithm}

The exact algorithm used by the exchange is not published. I recreate the algorithm here and show in the next section that my recreation matches published area-clearing prices very well. The algorithm runs as follows:

1. Clear the market in the constrained area $\mathcal{A}_{g}(p \mid \mathbf{L})$, beginning with the whole market.

2. Calculate regional net demands at the market-clearing price within the constrained area.

3. Calculate constraints from regional net demands

- Calculate difference between regional net demand and import margin or export margin for each region within the constrained area. 
- Calculate difference between implied interregional flows and total path constraints for each combination of regions within the constrained area.

\section{Check constraints}

- If any constraint violated:

- Update the definition of $\mathcal{A}_{g}(p \mid \mathbf{L})$ by partioning the grid on binding constraints.

- Attribute constrained flows into or out of $\mathcal{A}_{g}(p \mid \mathbf{L})$ to appropriate regions.

- If constraint applies within a previously constrained area relax the outer constraint.

- Return to (1.) for each constrained area separately.

- Otherwise exit.

Interregional flows are calculated by minimizing the sum of squared flows subject to meeting the regional net demands (i.e., to Kirchoff's First Law) and respecting binding constraints.

Figure B2 shows the application of the market-splitting algorithm in practice. The unconstrained solution implied a flow to the North region of $571 \mathrm{MW}$, in excess of its import capacity of $171 \mathrm{MW}$. The North region was therefore constrained apart from the rest of the grid and these two areas cleared separately, as shown in Figure B2, Panels A and B, with imports added to supply and exports to demand in each area. The importing North region has a clearing price about USD 20/MWh above the other regions and no further constraints bind once these areas are cleared separately. Bidders in each constrained area receive the area-clearing price in that area. ${ }^{39}$

\footnotetext{
${ }^{39}$ The difference between selling prices in exporting regions and buying prices in importing regions is retained by the system operator, under supervision of the regulator, in a Power System Development Fund. As of March 31, 2011 this fund held USD 91 million (INR 4.57 billion) in congestion revenues.
} 
Figure B2: Constrained Market Clearance

January 26th, 2010, hour 17

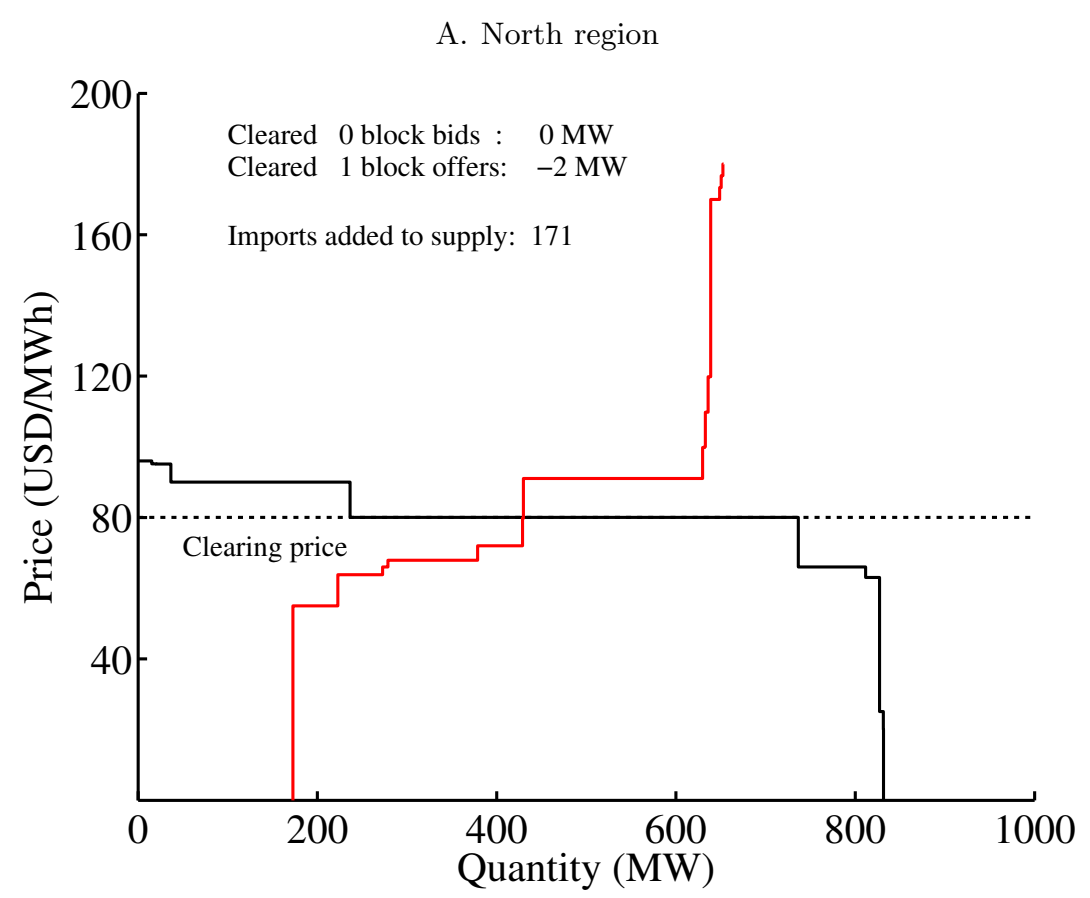

B. Other regions

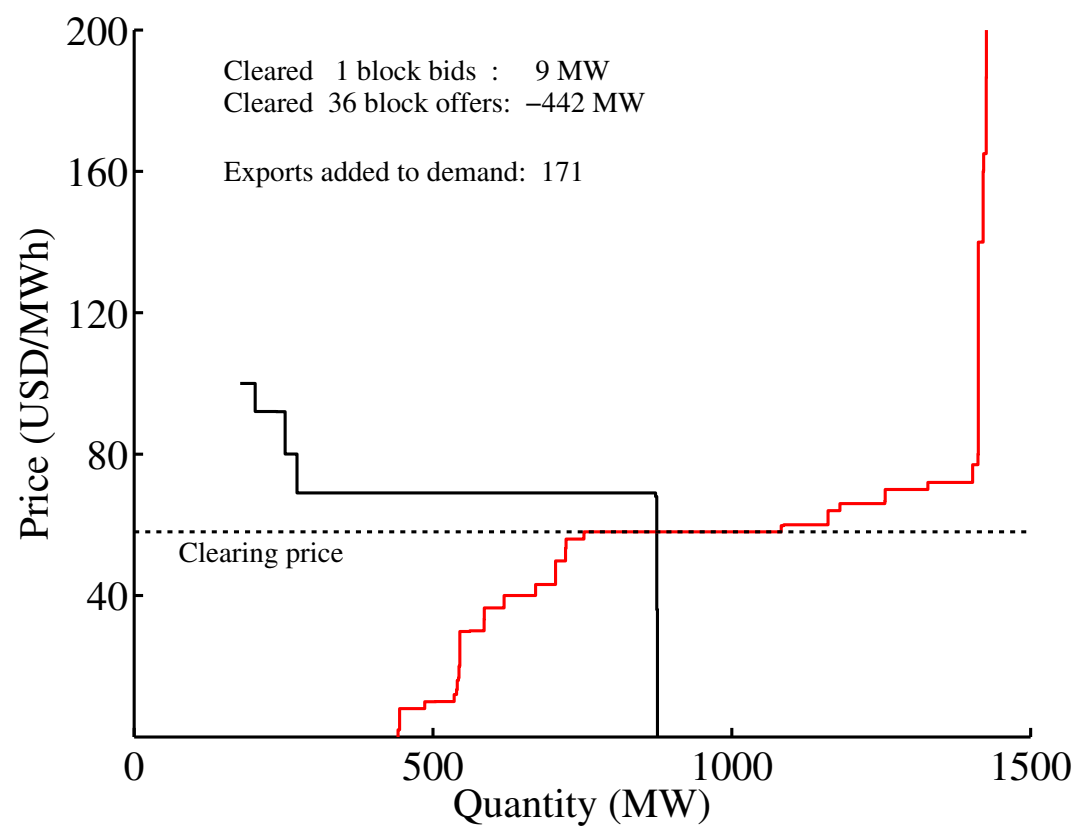

The figure shows the constrained market clearance on the Indian Energy Exchange during January 26th, 2010, hour 17. The unconstrained market clearance shown in Figure 2, Panel A implied a flow of 571 MW to North region when only $171 \mathrm{MW}$ of import capacity was available. The market was therefore split into one import constrained area consisting of the North region, shown in Panel A, and one export constrained area consisting of all other regions, shown in Panel B. The imports and exports have been added to the supply and demand curves in each respective panel. 
Table B3: Area-Clearing Price Differences

\begin{tabular}{|c|c|c|c|c|c|c|c|c|}
\hline \multirow[b]{2}{*}{ Quarter } & \multicolumn{4}{|c|}{ Unconstrained Clearance } & \multicolumn{4}{|c|}{ Constrained Clearance } \\
\hline & (1) & $\begin{array}{r}\text { Mean Price } \\
(2)\end{array}$ & $\begin{array}{c}\text { Abs Diff } \\
(3)\end{array}$ & $\begin{array}{l}\text { Pct Diff } \\
(4)\end{array}$ & $\begin{array}{l}\text { Hours } \\
\quad(5)\end{array}$ & $\begin{array}{r}\text { Mean Price } \\
(6)\end{array}$ & $\begin{array}{c}\text { Abs Diff } \\
\qquad(7)\end{array}$ & $\begin{array}{c}\text { Pct Diff } \\
(8)\end{array}$ \\
\hline 200901 & 2160 & 123.99 & 0.12 & 0.10 & 34 & 120.58 & 0.06 & 0.36 \\
\hline 200902 & 2184 & 155.43 & 0.30 & 0.19 & 776 & 106.28 & 0.84 & 1.44 \\
\hline 200903 & 2208 & 106.53 & 0.16 & 0.15 & 1192 & 86.27 & 1.47 & 2.40 \\
\hline 200904 & 2208 & 69.90 & 0.07 & 0.10 & 491 & 71.53 & 2.17 & 3.78 \\
\hline 201001 & 2160 & 82.16 & 0.13 & 0.16 & 1269 & 87.36 & 1.40 & 2.11 \\
\hline 201002 & 2184 & 106.02 & 0.15 & 0.14 & 420 & 119.64 & 1.01 & 0.91 \\
\hline 201003 & 2208 & 61.34 & 0.08 & 0.14 & 174 & 65.86 & 0.15 & 0.23 \\
\hline 201004 & 2208 & 46.92 & 0.05 & 0.11 & 934 & 57.22 & 1.12 & 1.96 \\
\hline 201101 & 2160 & 71.29 & 0.04 & 0.05 & 1695 & 96.98 & 0.63 & 0.41 \\
\hline
\end{tabular}

\section{(d) Accuracy of Market Clearing}

The replicated block-clearance and market-splitting algorithms are extremely accurate. I test their accuracy by comparing market prices reported by the IEX to those calculated by clearing the market with the bidding data.

Table B3 reports the results of the market clearance for each quarter from the first quarter of 2009 through the first quarter of 2011. The first four columns show the results for unconstrained clearance in all hours, regardless of whether the hour was constrained or not, as the exchange publishes prices for the unconstrained solution in all hours. The percentage difference betwen exchange prices and calculated prices, all in USD/MWh, is never more than 0.19 percent of the market clearing price in any single quarter and is more often around 0.10 percent. Columns 5 - 8 show the differences between the mean regional price reported and calculated during constraind hours. The errors are somewhat larger, with a maximum of 3.78 percent of the market clearing price across quarters, but still very small on average. The additional error in the constrained relative to the unconstrained price does not necessarily imply error in the market-splitting algorithm. Rather, on inspection, most of the hours when the two prices differ appear to be an interaction of transmission constraints with small changes in block clearance, which affect clearing prices more in relatively illiquid, constrained regions than in the market as a whole. 


\section{(e) Accuracy of Bootstrap Replications}

The estimation depends on accurately replicating the uncertainty faced by sellers over marketclearing prices and residual demand. This section briefly reports comparisons between the distribution of actual prices and the distribution of prices under the bootstrap replications of market outcomes for the single largest seller.

Table B4: Accuracy of Prices Simulated by Bootstrap (USD/MWh)

\begin{tabular}{lrrrrrr}
\hline & \multicolumn{2}{c}{ Unconstrained } & \multicolumn{2}{c}{ North } & \multicolumn{2}{c}{ West } \\
& Actual & Simulated & Actual & Simulated & Actual & Simulated \\
\hline Mean & 87.06 & 87.39 & 86.85 & 85.91 & 80.72 & 79.30 \\
Std & 48.52 & 48.44 & 48.52 & 48.36 & 48.06 & 48.27 \\
Skewness & 0.99 & 0.97 & 0.97 & 0.99 & 1.30 & 1.29 \\
Kurtosis & 3.90 & 3.95 & 3.86 & 4.04 & 4.54 & 4.68 \\
Min & 1.99 & 0.00 & 1.99 & 0.00 & 1.99 & 0.00 \\
p10 & 30.03 & 30.04 & 30.03 & 30.02 & 30.02 & 30.00 \\
p25 & 52.01 & 52.02 & 50.01 & 50.02 & 49.99 & 49.60 \\
p50 & 79.99 & 80.00 & 80.01 & 80.00 & 68.01 & 65.80 \\
p75 & 110.03 & 115.02 & 110.01 & 110.04 & 99.99 & 100.00 \\
p90 & 160.01 & 159.00 & 160.02 & 159.96 & 160.01 & 156.02 \\
Max & 278.01 & 295.36 & 278.01 & 360.02 & 278.01 & 400.00 \\
\hline
\end{tabular}

Table B4 shows moments of the actual and simulated price distribution for the Unconstrained, North and West prices, respectively. The means and standard deviations of the actual and simulated prices are very similar for each distribution. The simulated prices have slightly fatter tails, with floor prices observed in practice, unlike in the actual prices, and somewhat higher maximum prices. The bootstrap of bids at the daily level does not guarantee there will be demand bids in any given hour, hence generating the floor prices. The other, interior quantiles of the distribution match very closely. The right tails of the Unconstrained distribution, which reflects demand in the South region and the North region, and in the North region, are above the right tails in the West region from the median through the 75th percentile. Comparisons for the uncertainty faced by other sellers and in individual hours of the day also show similar distributions of actual and simulated clearing prices.

\section{(f) Smoothing of Residual Demand}

Both the estimation and counterfactual simulations model the residual demand as a smooth curve, rather than a step function. I approximate residual demand and its derivative with 
kernel-smoothed functions in the manner of Wolak (2007). Let $j$ index bids from both the demand and supply sides, where $q_{j k}$ is the incremental increase in supply or decrease in demand from firm $j$ above price $p_{j k}$. Let $D^{g}\left(0, \sigma_{-i t}\right)$ be the total demand in the area of region $g$ at a price of zero and $\mathcal{A}_{g}$ be short for $\mathcal{A}_{g}(p \mid \mathbf{L})$. Then residual demand and its derivative are approximated using a normal kernel as:

$$
\begin{aligned}
\tilde{D}_{i t}^{r g}\left(p \mid \sigma_{-i}, \mathcal{L}_{t}\right) & =-\sum_{j \neq i, j \in \mathcal{A}_{g}} \sum_{k} q_{j k} \Phi\left(\frac{p-p_{j k}}{w}\right) \\
\frac{\partial \tilde{D}_{i t}^{r g}\left(p \mid \sigma^{\mathbf{s}}{ }_{-i}, \mathcal{L}_{t}\right)}{\partial p} & =-\frac{1}{w} \sum_{j \neq i, j \in \mathcal{A}_{g}} \sum_{k} q_{j k} \phi\left(\frac{p-p_{j k}}{w}\right) .
\end{aligned}
$$

The bandwidth $w$ controls the degree of smoothing, with a larger bandwidth smoothing the curve more. I set $w=$ USD $10 / \mathrm{MWh}$ in the estimation, which is 11 percent of the mean unconstrained market-clearing price and 0.21 standard deviations in this price. Ownsupply is smoothed in a similar manner. Following Wolak (2007), the derivatives of residual demand and own-supply then form the weights of the first-order condition as $\frac{\partial p}{\partial b_{i t k}}=$ $\frac{\partial q_{i t}(p)}{\partial b_{i t k}} /\left(\frac{\partial D_{i t}^{r g}(p)}{\partial p}-\frac{\partial q_{i t}(p)}{\partial p}\right)$, by the implicit function theorem.

In Table B5 I test the robustness of the cost estimates to different smoothing parameters and to not instrumenting the moment conditions with lagged temperature.

The main IV estimates of marginal cost are in column 6 and column 2 reports estimates without instruments. The mean marginal cost estimates across all bidders is a modest 8 percent higher in the main IV estimates, reducing bidder margins, and the mean absolute deviation between the baseline and IV estimates is also 8 percent. Endogeneity of bids driven by cost shocks appears a mild concern in this market, perhaps because few supply shocks are realized by the time offers are made, a day ahead of delivery.

In column (4) I present estimates of marginal cost without IV using a smoothing parameter 50 percent larger than in the baseline case (i.e., $w=$ USD 15/MWh instead of USD 10/MWh). Because the smoothing parameter partly determines the elasticity of residual demand, it changes the moment conditions, and one may be concerned that this parameter arbitrarily influences the estimates of marginal cost. The estimates are practically unchanged, with the mean cost estimate higher by 0.42 percent and the mean absolute deviation over all cost estimates only 3.42 percent, relative to column (2). The estimated costs thus do not appear 
Table B5: Robustness of Estimated Marginal Costs (USD/MWh)

\begin{tabular}{|c|c|c|c|c|c|c|}
\hline $\begin{array}{c}\text { Wtd. Mean } \\
\text { Tick Price } \\
(1)\end{array}$ & $\begin{array}{r}\mathrm{IV}=\text { No, } \mathrm{w} \\
\text { Estimated } \\
\text { Marginal Cost } \\
(2)\end{array}$ & $\begin{array}{l}=10 \\
\text { Std. Err. } \\
\end{array}$ & $\begin{array}{r}\mathrm{IV}=\text { No, } \mathrm{w} \\
\text { Estimated } \\
\text { Marginal Cost } \\
(4)\end{array}$ & $\begin{array}{l}\text { Std. Err. } \\
(5)\end{array}$ & $\begin{array}{r}\mathrm{IV}=\text { Yes, } \\
\text { Estimated } \\
\text { Marginal Cost } \\
(6)\end{array}$ & $\begin{array}{c}\text { Std. Err. } \\
(7)\end{array}$ \\
\hline 93.35 & 75.66 & $(7.44)$ & 76.36 & $(5.81)$ & 84.42 & $(6.93)$ \\
\hline 60.41 & 47.18 & $(1.79)$ & 48.94 & $(1.94)$ & 57.47 & $(2.80)$ \\
\hline 73.39 & 56.85 & $(3.20)$ & 57.59 & $(2.99)$ & 68.91 & $(4.49)$ \\
\hline 87.54 & 82.64 & $(6.21)$ & 83.27 & $(7.60)$ & 100.01 & $(7.61)$ \\
\hline 73.20 & 61.68 & (1.37) & 60.92 & $(1.58)$ & 64.32 & $(1.55)$ \\
\hline 48.46 & 36.66 & (1.09) & 36.59 & $(1.00)$ & 39.98 & $(1.14)$ \\
\hline 91.32 & 80.71 & $(2.22)$ & 80.22 & $(2.11)$ & 80.90 & $(2.02)$ \\
\hline 35.98 & 19.17 & $(1.07)$ & 19.24 & $(1.08)$ & 20.58 & $(1.32)$ \\
\hline 66.86 & 58.56 & $(0.79)$ & 58.28 & $(0.94)$ & 59.68 & $(1.01)$ \\
\hline 109.98 & 62.30 & $(2.84)$ & 67.32 & $(2.91)$ & 65.64 & $(3.43)$ \\
\hline 132.39 & 118.86 & $(3.95)$ & 119.17 & $(3.56)$ & 121.05 & $(3.94)$ \\
\hline 36.57 & 45.33 & $(0.52)$ & 44.46 & $(0.53)$ & 45.06 & $(0.76)$ \\
\hline 14.90 & 14.08 & (1.97) & 10.53 & $(1.24)$ & 14.32 & $(2.12)$ \\
\hline \multicolumn{7}{|c|}{ Column Means } \\
\hline 71.10 & 58.44 & & 58.68 & & 63.25 & \\
\hline
\end{tabular}

The table shows robustness checks for the cost estimates of Table 4. The rows represent strategic sellers ordered as in that table. Strategic sellers are those sellers in the North and West region with at least one percent market share as determined by the share of offered volume. Columns 2 and 3 give the coefficients and standard errors for the estimates without instrumental variables and with a bandwidth of USD 10/MWh for smoothing residual demand. Columns 4 and 5 give estimates using a larger bandwidth of USD 15/MWh. Columns 6 and 7 give the Table 4 estimates at the original bandwidth and using lagged temperature as an instrument for the moment conditions, on the assumption that lagged temperature shifts expected demand but does not affect supply shocks. Standard errors are bootstrapped by resampling 100 bootstrap iterations with replacement from the set of moment conditions.

very sensitive to a marginal change in the degree of smoothing.

\section{(g) Cournot model equilibrium conditions and solution method}

Consider a set of strategic firms $i$ with marginal costs $\gamma_{i}$ facing a residual demand curve $D^{g}\left(p \mid \sigma_{-i t}, \mathcal{L}_{t}\right)$ with a twice-continuously differentiable inverse residual demand curve $\tilde{P}^{g}\left(Q^{g} \mid \sigma_{-i t}, \mathcal{L}_{t}\right)$, where $Q^{g}$ is aggregate strategic quantity offered in region $g$ by all strategic firms together. For now, take the division of the market into regions $g$ as exogenously given; I will discuss how the regions are determined below.

The derivative of profit with respect to the seller's offered quantity $q_{i t}$ is:

$$
\left.f_{i t}\left(q_{i t}\right)=\tilde{P}^{g}\left(Q^{g} \mid \sigma_{-i t}, \mathcal{L}_{t}\right)+q_{i t} \tilde{P}^{g \prime}\left(Q^{g} \mid \sigma_{-i t}, \mathcal{L}_{t}\right)\right)-\gamma_{i}
$$


Necessary and sufficient conditions for an equilibrium set of quantities are that for all strategic sellers $i$ :

$$
\begin{array}{rll}
q_{i t} \in\left(0, \bar{q}_{i}\right) & \perp \quad f_{i t}\left(q_{i t}\right) \neq 0 \\
q_{i t}=0 & \perp \quad f_{i t}\left(q_{i t}\right) \geq 0 \\
q_{i t}=\bar{q}_{i} & \perp \quad f_{i t}\left(q_{i t}\right) \leq 0 .
\end{array}
$$

Here $\bar{q}_{i}$ is the maximum quantity that a strategic seller can offer, due to capacity constraints. The form of this problem is a mixed-integer complementary problem, since the equilibrium conditions are complementarity conditions between capacity constraints binding and the firm's first-order condition for an interior quantity. If the seller produces an interior quantity, between zero and their constraint, then it must be that the derivative of profits with respect to quantity at that point is zero. Similarly, if the seller produces nothing this derivative must be negative, else they would increase quantity, and if the seller produces at their quantity constraint this derivative must be positive, else they would decrease quantity.

The conditions for profit maximization depend on the first and second derivatives of inverse residual demand with respect to quantity. I represent inverse residual demand function $\tilde{P}^{g}$ as a set of whole quantities and incremental prices and smooth over quantities, with the same kernel-smoothing method described in , in order to approximate the derivative of inverse residual demand. When smoothing over quantity I use a bandwidth $w_{q}$ equal to ten percent of the range of quantities spanned by the residual demand curve.

The problem is linear in $q_{i t}$ if one neglects the effect of each seller's quantity on the aggregate $Q^{g}$. Similarly to Bushnell, Mansur and Saravia (2008), I solve this problem with the sequential linear complementarity problem approach of Kolstad and Mathiesen (1991) using the PATH algorithm on each iteration (Dirkse and Ferris, 1995). This algorithm solves a linear complementarity problem for a vector of $q_{i t}$ on each iteration and then sequentially updates $Q^{g}$ to formulate another linear problem, repeating the process until convergence. Sufficient conditions for the uniqueness of Cournot equilibria generally require pseudoconcavity of profit functions (Kolstad and Mathiesen, 1987). Given constant marginal costs, the profit functions must inherit this property from the demand function.

The regions $g$ into which the grid is divided are determined by nesting the Cournot prob- 
lem within the market-splitting algorithm, described in Appendix B (c), which deals with constraints in practice. The treatment of congestion in the counterfactuals is therefore the same as in estimation. That is, the Cournot model is first solved on the unconstrained grid, and the equilibrium prices, quantities and inter-regional flows are calculated. If these flows and the implied regional imports and exports violate any transmission constraints, then those constraints are assumed binding, and a new Cournot equilibrium is solved on the constrained grid divided by these constraints. Iterations continue until an equilibrium is found and no additional constraints bind, as described in the market-splitting algorithm.

The implication of this algorithm for the model is that strategic sellers behave with certainty that the grid constraints will bind as they do in equilibrium, and that strategic sellers account for the effects of inelastic equilibrium imports and exports in their bids. The firstorder conditions of strategic sellers are confined to their constrained regions, and will be altered by both the slope and the level effects described in Section 2 (b). Strategic sellers do not, however, 'see through' the iterations of the market-splitting constraint to account for the endogeneity of the constraints with respect to their bids. This assumption strongly simplifies the problem and is realistic given the relative non-concentration of the unconstrained grid.

\section{(h) Uniqueness of counterfactual Cournot equilibrium}

The Cournot model used does not theoretically guarantee a unique equilibrium here, for two reasons. The first reason the equilibrium may not be unique is the presence of transmission constraints. Transmission constraints can produce multiple equilibria, with lines congested in different directions, or leave no pure-strategy equilibria at all. In markets with asymmetric firms and demand across regions, a pure-strategy equilibrium of the Cournot model will virtually always exist: the condition necessary for two regions is only that the two regions have different monopoly prices (Borenstein, Bushnell and Stoft, 2000). The asymmetry in the Indian day-ahead market between a relatively low-priced central core, of the West and North region, and a high-priced periphery, of the North and South, suggests there will be a single pure-strategy equilibrium, as it will not be worthwhile, or even possible, for the suppliers in power-scarce regions to congest the line outwards in order to gain market share from relatively abundant regions.

The second reason that the equilibrium may not be unique is that the residual demand 
curve here is not always pseudoconcave. Because I smooth inverse residual demand but do not otherwise restrict its shape, it can alternate between concave and convex regions at different quantities, which may, but will not necessarily, admit multiple equilibria at different clearing volumes.

Empirically, I search for multiple equilibria, by starting the equilibrium search at different quantities, but generally find a unique equilibrium for every hour. In the baseline simulation I initialize the search for an equilibrium at the point where all strategic sellers have equal quantities and supply 75 percent of the maximum residual demand. This could in principle lead to selection of local equilibria further out on the demand curve than the actual equilibria selected by firms, in accord with the discussion of Section 4 (b). I test for the importance of equilibrium selection by instead allocating strategic sellers 25 percent of the maximum residual demand to start. This produces an average unconstrained market price of USD 73.78/MWh over the sample period, indistinguishable from the price of USD 73.74/MWh in the baseline simulation, indicating that a different equilibrium has been found in at most a handful of hours. The two simulations also match exactly on other dimensions of congestion and market volume.

Therefore, though I cannot rule out multiple equilibria, multiplicity does not appear to be important in practice. I speculate that this is due to the typical shape of the demand curve. In many hours, the demand curve is inelastic at low and high prices and elastic at moderate prices, as in Figure B2, Panel B. ${ }^{40}$ In principle, this can create distinct concave portions of residual demand where equilibria might be found. In practice, though, the potential equilibrium higher up the residual demand curve are at very low or even negative quantities, and sellers can increase profits in this part of the curve by selling more, even if it brings prices down.

\footnotetext{
${ }^{40}$ The extreme elasticity at moderate prices comes mainly from industrial consumers that have outside options of purchasing from unscheduled interchange or from state suppliers at prices in this range.
} 